\title{
Integrated in silico MS-based phosphoproteomics and network enrichment analysis of RASopathy proteins
}

Javier-Fernando Montero-Bullón ${ }^{1}$, Óscar González-Velasco², María Isidoro-García ${ }^{3,4,5,6}$ and Jesus Lacal $3,7^{*}$ (i)

\begin{abstract}
Background: RASopathies are a group of syndromes showing clinical overlap caused by mutations in genes affecting the RAS-MAPK pathway. Consequent disruption on cellular signaling leads and is driven by phosphoproteome remodeling. However, we still lack a comprehensive picture of the different key players and altered downstream effectors.
\end{abstract}

Methods: An in silico interactome of RASopathy proteins was generated using pathway enrichment analysis/STRING tool, including identification of main hub proteins. We also integrated phosphoproteomic and immunoblotting studies using previous published information on RASopathy proteins and their neighbors in the context of RASopathy syndromes. Data from Phosphosite database (www.phosphosite.org) was collected in order to obtain the potential phosphosites subjected to regulation in the 27 causative RASopathy proteins. We compiled a dataset of dysregulated phosphosites in RASopathies, searched for commonalities between syndromes in harmonized data, and analyzed the role of phosphorylation in the syndromes by the identification of key players between the causative RASopathy proteins and the associated interactome.

Results: In this study, we provide a curated data set of 27 causative RASopathy genes, identify up to 511 proteinprotein associations using pathway enrichment analysis/STRING tool, and identify 12 nodes as main hub proteins. We found that a large group of proteins contain tyrosine residues and their biological processes include but are not limited to the nervous system. Harmonizing published RASopathy phosphoproteomic and immunoblotting studies we identified a total of 147 phosphosites with increased phosphorylation, whereas 47 have reduced phosphorylation. The PKB signaling pathway is the most represented among the dysregulated phosphoproteins within the RASopathy proteins and their neighbors, followed by phosphoproteins implicated in the regulation of cell proliferation and the MAPK pathway.

Conclusions: This work illustrates the complex network underlying the RASopathies and the potential of phosphoproteomics for dissecting the molecular mechanisms in these syndromes. A combined study of associated genes, their interactome and phosphorylation events in RASopathies, elucidates key players and mechanisms to direct future research, diagnosis and therapeutic windows.

Keywords: Phosphoproteomics, Interactomics, RASopathies, Neurofibromatosis, Noonan syndrome, Mass spectrometry, Rare diseases

\footnotetext{
*Correspondence: jlacal@usal.es

${ }^{3}$ Institute for Biomedical Research of Salamanca (IBSAL),

37007 Salamanca, Spain

Full list of author information is available at the end of the article
}

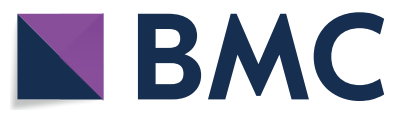

(c) The Author(s) 2021. Open Access This article is licensed under a Creative Commons Attribution 4.0 International License, which permits use, sharing, adaptation, distribution and reproduction in any medium or format, as long as you give appropriate credit to the original author(s) and the source, provide a link to the Creative Commons licence, and indicate if changes were made. The images or other third party material in this article are included in the article's Creative Commons licence, unless indicated otherwise in a credit line to the material. If material is not included in the article's Creative Commons licence and your intended use is not permitted by statutory regulation or exceeds the permitted use, you will need to obtain permission directly from the copyright holder. To view a copy of this licence, visit http://creativecommons.org/licenses/by/4.0/. The Creative Commons Public Domain Dedication waiver (http://creativeco mmons.org/publicdomain/zero/1.0/) applies to the data made available in this article, unless otherwise stated in a credit line to the data. 


\section{Background}

RASopathies are a group of phenotypically overlapping syndromes caused by germline mutations that encode components of the RAS/MAPK signaling pathway, affecting growth and development $[1,2]$. The RAS/ MAPK signaling pathway is a chain of proteins in the cell that communicates a signal from a receptor on the surface of the cell to the DNA, and has major impact in human health [2-4]. These disorders include neurofibromatosis type 1 (NF1), Legius syndrome (LS), Noonan syndrome (NS), neurofibromatosis-Noonan syndrome (NFNS), Noonan syndrome-like (NSL), Noonan syndrome with multiple lentigines (NSML), formerly known as LEOPARD syndrome, Noonan syndrome-like with loose anagen hair (NSLSH) also known as Mazzanti syndrome, Costello syndrome (CS), cardiofaciocutaneous (CFC) syndrome, capillary malformation-arteriovenous malformation syndrome (CM-AVM), intellectual disability associated with autism spectrum disorder and juvenile myelomonocytic leukemia (JMML) [3-5]. To date, mutations in 27 genes have been proven as cause of these RASopathies (Fig. 1).

Neurofibromatosis type 1 (NF1) is caused by mutations in the NF1 gene [6], whereas Legius syndrome, also known as NF1-like syndrome, is caused by mutations in the SPRED1 gene [7]. Mutations in 13 genes so far, have been reported to underlie the Noonan syndrome (NS), the most genetically diverse RASopathy and the most common. Approximately $80 \%$ of individuals with NS harbor mutations in genes whose products are involved in the RAS/MAPK pathway including PTPN11 [8-12] in about half of all cases, $S O S 1[8,9,11-14]$ in an additional 10 to $15 \%, R A F 1[8,9,11,12,14-17]$ and RIT1 [12, $18-20]$ in about an additional 5\%. The remaining underlying genetic causes in nearly $20 \%$ of individuals with NS includes pathogenic variants in $B R A F[8,21], K R A S$ [8, 12, 14, 22, 23], LZTR1 [12, 24-27], MAP2K1 [23, 28, 29], MRAS [30-32], NRAS [12, 33-35], RASA2 [29, 36], RRAS2 [29, 37, 38] and SOS2 [24]. Further clinical and genetic analysis is required to establish the pathogenic significance for some of these genes, including RASA2, SOS2 and BRAF. About 3\% of all affected individuals with NS correspond to additional unidentified genes. Neurofibromatosis-Noonan syndrome (NFNS) is a rare condition with clinical features of both NF1 and NS. The major gene involved in NFNS is NF1, but co-occurring NF1 and PTPN11 mutations have been reported [29, 39].

Patients with NF1, and Noonan syndrome, have a higher risk of developing juvenile myelomonocytic myeloid leukemia (JMML) [40]. Recently considered as a bona fide RASopathy [4], JMML is a rare clonal myelodysplastic/myeloproliferative neoplasm of early childhood

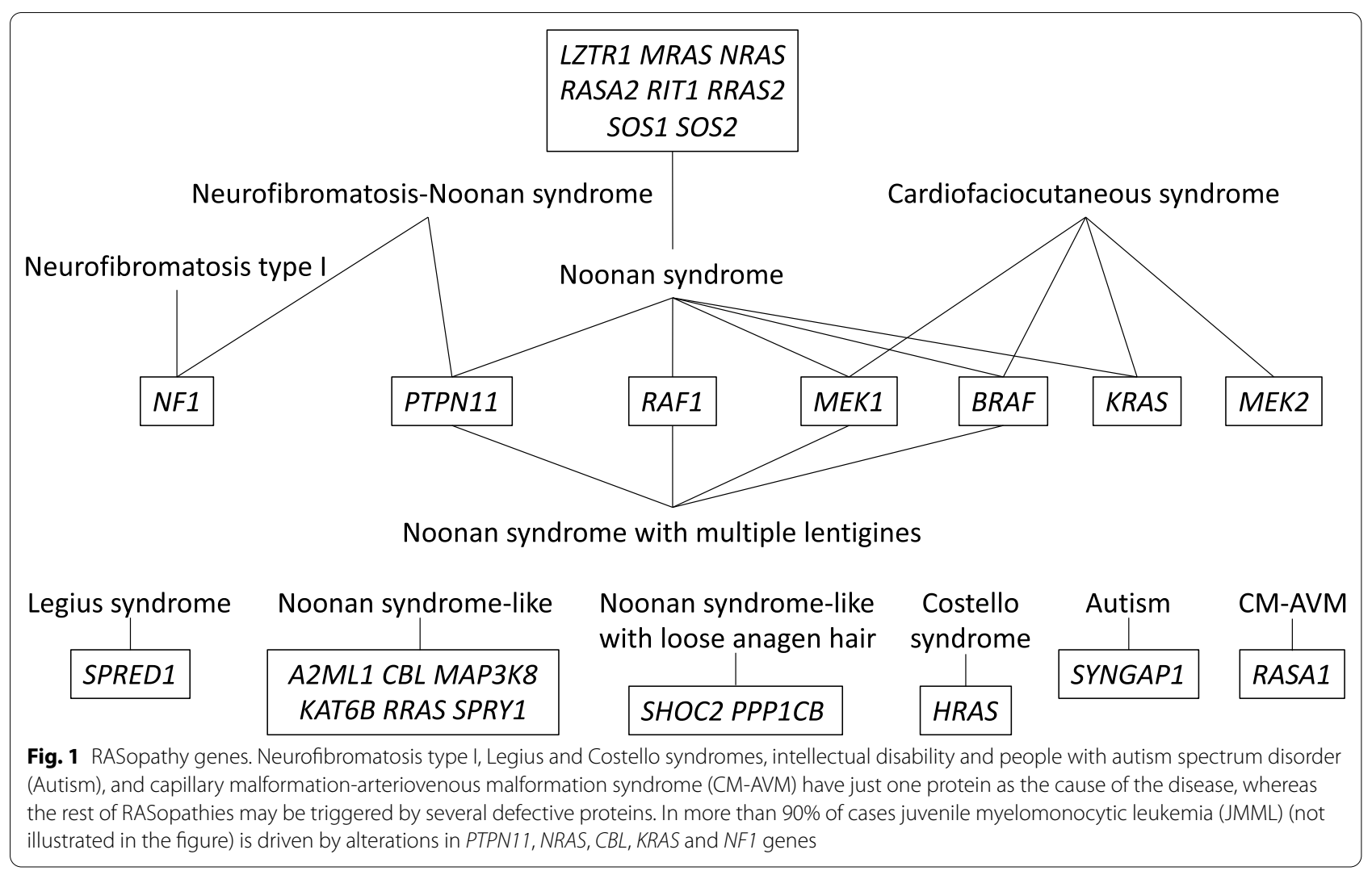


caused by hyperactive RAS signaling [41]. About $90 \%$ of patients with JMML harbor molecular alterations in 1 of 5 genes, all of them encoding RASopathy proteins. Genes that increase the risk of developing JMML include NF1 (5-12\%), PTPN11 (37-38\%), KRAS (17-18\%), NRAS (14\%) and $C B L$ (9-18\%) [42-44]. Minority genes responsible for JMML include ARHGAP26 [45], PCR2 and RAC2 [46], JAK3 and SETBP1 [47, 48], and presumably SPECC1 along with CTSB and PDGFRB [49].

Noonan syndrome-like is caused by a group of genes other than the common ones for NS, including mutations in A2ML1 [50], CBL [9, 12, 51], MAP3K8 [29], MYST4/KAT6B [52], RRAS [53] and SPRY1 [8, 29]. Noonan syndrome with multiple lentigines (NSML) can be of 3 types, which are distinguished by their genetic cause. Type 1 , corresponding to $90 \%$ of all cases, is caused by mutations in the PTPN11 gene $[8,9,11,15]$. Type 2 is caused by mutations in RAF1 [15]. Type 3 is caused by mutations in $B R A F$ [21]. Others are caused by mutations in $M E K 1$ [54], and in some cases the cause is unknown. Noonan syndrome-like with loose anagen hair (NSLSH) is caused by mutations in the $S H O C 2[8,12,14,55,56]$ and $P P P 1 C B$ genes $[57,58]$.

Costello syndrome is caused by mutations in the HRAS gene $[8,11,59]$. The features of Costello syndrome overlap significantly with two of the RASopathies, NS and CFC. Likewise, CFC overlaps significantly with Costello and Noonan syndromes. CFC syndrome can be caused by mutations in several genes including $B R A F[8,9,11$, $14,21,23,60]$ with approximately $75 \%$ of all cases, $M E K 1$ $[8,23,61]$ and $M E K 2[9,14,23,62,63]$ with another 10 to $15 \%$, and KRAS $[23,60,64]$ with fewer than $5 \%$.

SYNGAP1 was identified as a protein causing autosomal dominant intellectual disability type 5 [65], and as a causative RASopathy protein [26]. SYNGAP1-related intellectual disability and some rare mutations in $S Y N$ GAP1 are associated with autism spectrum disorder [65, 66]. However, more basic research is needed to better understand the molecular and cellular functions of this protein [67].

On top of its major role in cancer [68], heterozygousinactivating mutations in RASA1 cause the autosomal dominant capillary malformation-arteriovenous malformation syndrome (CM-AVM) [69-71]. In this study we have included 5 more genes that do not belong to the classical RASopathy genes but were included in a gene panel towards the molecular diagnosis of Noonan syndrome and other RASopathies by Institut für Medizinische Genetik (https://www.medgen.uzh.ch/de.html): ANKRD11 [72], FGFR3 [73-75], MEF2C [76, 77], SHOX [78-81], and SRCAP [68, 82]. Also, their clinical features due to their molecular implications when mutated are common to most RASopathy syndromes.
Phosphoproteomics is a valuable approach to understand diseases linked to phosphorylation events, and it has a potential value for the clinics and for a personalized medicine [83, 84]. Classical immunoblot assays have been used to study phosphorylated amino acids in RASopathy proteins [85-87]. Whereas with the advent of more sensitive and accurate liquid chromatography-mass spectrometry (LC-MS) instrumentation, the number of large-scale mass spectrometry-based phosphoproteomic studies has swelled over the past decade [88], initiating its application to RASopathies [85, 89-92]. These techniques should allow to pinpoint biologically relevant phosphorylation events of utmost importance in the mechanisms of RASopathies [5]. However, only a few studies focused on their dysregulated phosphoproteins and their biological implications. Approaches mimicked mutations found in human samples associated to NS, NSML, and NF1 [85-87, 89-94]. In NF1 studies, NF1null cells derived from malignant peripheral nerve sheath tumors (MPNST) showed RAS cascade hyperactivation typical of NF1. The interplay of H-Ras, N-Ras, and K-Ras produced a counter-inhibition of these classical Ras proteins, revealing an intense phosphoproteome remodeling [89]. Other studies were also conducted focusing on proteins such as CRMP-2 [93] and dynein IC2-C [85]. RAF1 [86], BRAF [94], PZR and SIRPa [87] are related to both NS and NSML, and changes in their phosphorylation were also observed. High-throughput screening strategies based on mass spectrometry have also been used to study NS and NSML [90-92], revealing dozens of dysregulated phosphoproteins.

The current state of knowledge about the RASopathy interactome is mainly based on an integrated network presented at genome, interactome, and phenome levels [1]; Twelve causative genes and clinical symptoms were collected from OMIM and NCBI GeneReviews databases for 6 syndromes: NS, NSML, NF1, CFC, Legius and Costello syndrome. In particular, they created an interactome network based on interactions between 12 proteins (PTPN11, SOS1, RAF1, BRAF, KRAS, NRAS, HRAS, MAP2K1, MAP2K2, SPRED1, NF1, and RIT1) of the RASopathies and another one based on their 10 first neighbors. However, we still lack a comprehensive view about the protein-protein associations involved in all RASopathy proteins and their neighbors. Mutations in some of these genes may drive RASopathies, cancer, or both in the same patient, but that is something that needs to be empirically tested. Phosphoproteomics data in RASopathies is still scarce and its potential to decipher crucial signaling pathways involved in this family of disorders needs to be considered. The application of LC-MS analysis, relying on high-sensitive nanoflow setups and 
phosphoprotein enrichment, is encouraged to unveil underlying molecular mechanisms affected in these syndromes, and suggest therapeutic targets for clinical implementation.

In this work, we aim to provide an up to date panel of proteins underlying RASopathies in order to identify protein-protein associations, and assign them to their cognate syndromes. The interactome was further analyzed in silico by binary interactions between the RASopathy proteins, a search for main hub proteins in the interactome and their classification based on GO terms for biological processes. We also carried out an analysis of phosphorylation level changes in the proteins from the RASopathy interactome integrating previous phosphoproteomic studies in the context of RASopathy syndromes. Finally, we analyzed the phosphosite abundance in causative RASopathy proteins in silico.

\section{Results}

RASopathy protein-protein associations

In order to identify protein-protein associations within the RASopathy proteins we used STRING database to download a subgraph composed of the initially 32 RASopathy proteins selected in this study. Among the panel of 32 RASopathy proteins, our results show that 6 proteins belong to the RAS family, 15 are directly associated with RAS, and 11 proteins do not seem to be associated with RAS (Fig. 2A). RAS includes the classical RAS (H-RAS, K-RAS and N-RAS) and the three RRAS (RRAS, RRAS2 and RRAS3/MRAS). The 11 proteins that do not directly associate with RAS are ANKRD11, MEF2C, SHOX and SRCAP (aforementioned as non-classical RASopathy proteins), KAT6B, CBL, MAP3K8 and A2ML1 (which cause NSL), LZTR1 and RIT1 (responsible for NS), and PPP1CB (which causes NSLSH). The proteins that associate with all RAS include but are not limited to BRAF, RAF1, as well as several guanine nucleotide exchange

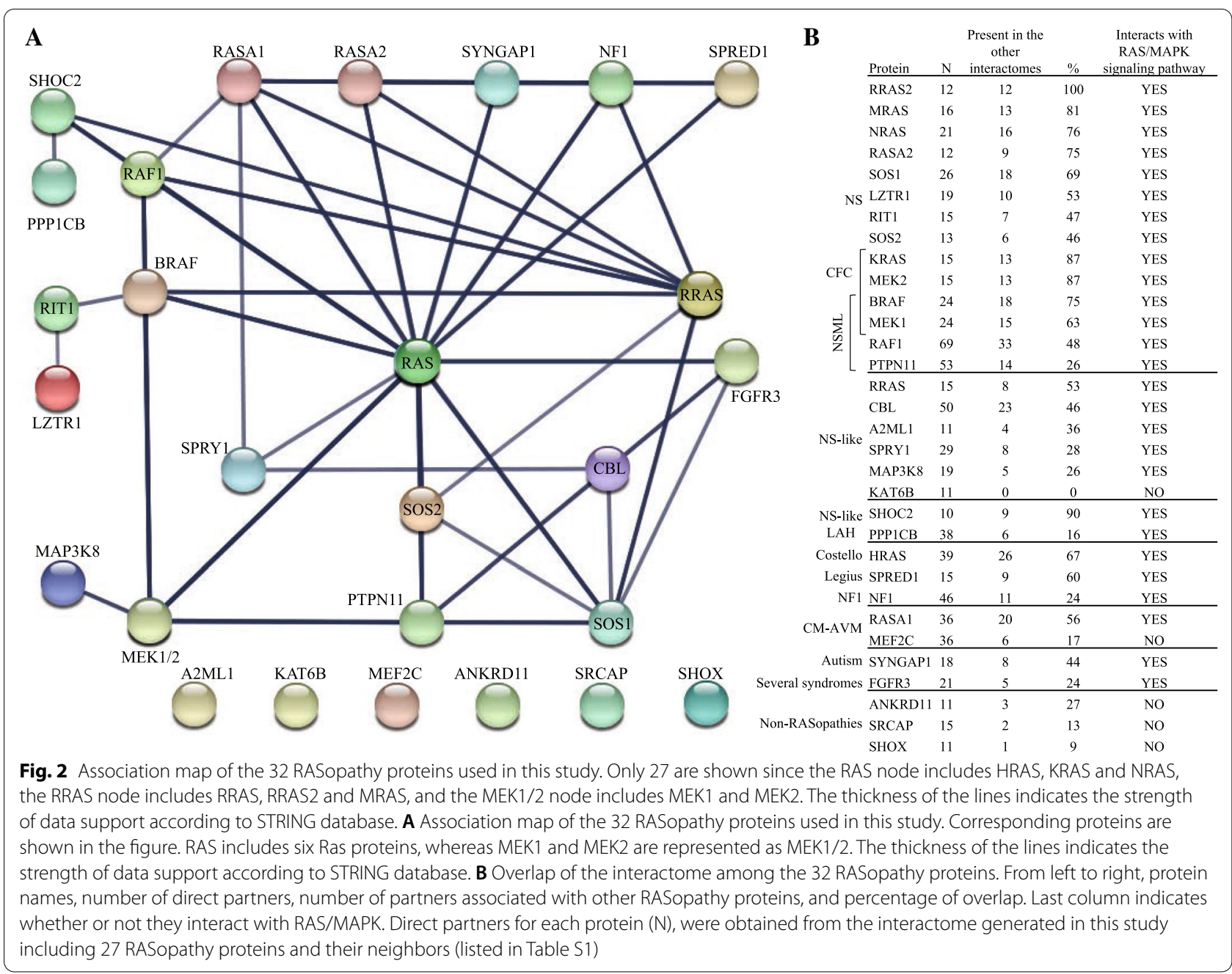


factors (GEFs) and GTPase-activating proteins (GAPs) that regulate RAS activity (Fig. 2A).

We then generated an interactome for the 32 RASopathy proteins including their direct interacting partners. This interactome contains a total of 765 proteins. Some of them were found associated to more than one RASopathy protein and therefore they appeared duplicated. When eliminating the duplicated proteins, we ended up with 511 unique proteins based on unique UniProt IDs (Additional file 1). On average, the overlap of the interactome among the 32 RASopathy proteins is $56 \%$. According to our results, RRAS2 interactome fully overlaps with other RASopathy protein's interactome, followed by SHOC2 (90\%), MEK2 (87\%) and RAS (87-53\%) among other proteins (Fig. 2B). Interestingly, FGFR3 did show direct interaction with RAS, was previously shown to exert and impact on RAS-MAPK signaling pathway [7375 ] and had an interactome overlap of $24 \%$ with other RASopathy protein neighbors (Fig. 2B). On the other hand, ANKRD11, MEF2C, SRCAP, SHOX and KAT6B does not interact with RAS/MAPK and they show a low overlap (Fig. 2B). Therefore, they were not considered for further analyses in this study. However, A2ML1 was not excluded because according to our results A2ML1 interactome has a protein-protein association overlap with the rest of the RASopathy interactomes above $25 \%$, which is even higher than the one obtained for other RASopathy proteins. Also, A2ML1 may interacts with the RAS-MAPK signaling pathway; A2ML1 is known to bind to lipoprotein receptor-related protein 1 activating of the Ras/MAPK pathway through its association with SHC domain proteins and CBL during recruitment to the plasma membrane $[95,96]$. Considering the above data, from the initial 32 RASopathy proteins we continue studying 27 proteins, excluding ANKRD11, KAT6B, MEF2C, SHOX and SRCAP from further analyses.

\section{The interactome of RASopathy proteins by syndrome}

The interactome of 27 RASopathy proteins including their direct interacting partners, yield a total of 687 proteins (432 unique entries based on UniProt IDs). These proteins were assigned to their cognate syndromes in order to identify their occurrence by syndrome, purely reflecting the number of proteins associated with the syndrome (Fig. 3A). Our results show that the largest overlap correspond to NS with a total of 196 proteins (41.2\%) shared with other RASopathy interactomes. On the other hand, FGFR3-related syndromes had the smallest overlap with only 4 proteins $(0.8 \%)$ (Fig. $3 \mathrm{~A}$ ).

The analysis of all possible binary interactions between the interactome of each of the RASopathy proteins shows that 124 out of 351 binary interactions do not have in common a single protein (Additional file 2). Our results also show that 185 binary interactions share between 1 and 5 proteins, 38 between 6 and 10, and only 4 binary interactions share more than 10 proteins in their interactomes. This last set of binary interactions was found between HRAS and NRAS with 15 proteins, followed by BRAF and RAF1 with 14 proteins, HRAS and KRAS with 11 proteins, and HRAS and RRAS2 with 11 proteins (Additional file 2).

A search for main hub proteins in the interactome resulted in 12 nodes. The protein corresponding to the node with most associations with other genes within the RASopathy interactome is AKT1 with 199 associations reported. The second node with more interactions, 186 edges, corresponds to HRAS. PIK3R1 is the third with 124 known interactions. SRC yielded 118 interactions, SOS reported 109 interactions, GRB2 has 104, and CDC42 has 100 interactions. Other highly connected nodes found on the interactome network were NRAS with 94 interactions, SHC1 with 87, PPP2CA reporting 77, BDNF with 76 and JNK1 with 76 interactions.

An enrichment analysis based on GO terms for biological processes was done using the 432 unique proteins (Fig. 3B). Interestingly the largest group of proteins correspond to proteins with phosphorylated tyrosine residues. Followed in abundance by PKB, RAS and MAPK signaling proteins, phosphatase activity and PIP3 biosynthesis and signaling proteins (Fig. 3B). We also found that several biological processes directly related with the nervous system may be altered, such as axonogenesis, peripheral nervous system development and neuron apoptosis.

\section{Analysis of dysregulated phosphoproteins in RASopathies}

Functional annotation clustering of the interactome of the 27 RASopathy proteins and their interacting partners shows that 370 out of 432 proteins are annotated as phosphoproteins (Additional file 3). In order to study dysregulated phosphoproteins in RASopathies, protein phosphorylation level changes associated to RASopathies were compiled (Additional file 4) from nine phosphoproteomic (Fig. 4A) and twenty-seven immunoblotting studies (Table 1). The analysis of phosphorylation protein level changes within the RASopathy interactome comprises a total of 37 phosphoproteins (Additional file 5). In total and by syndrome, phosphoproteomic studies show that 8 phosphosites from 3 proteins are dysregulated in NF1, 53 phosphosites from 21 proteins in NS, 75 phosphosites from 31 proteins in NSML, 1 phosphosite in NSL, 2 phosphosites from 3 proteins in NSLH, 3 phosphosites from 2 proteins in LS, 4 phosphosites from 2 proteins in CS, 9 phosphosites from 3 proteins in CFC and 2 phosphosites from 2 proteins in JMML (crossing Additional file 1 and Additional file 4). Immunoblotting results show that dysregulation on several 

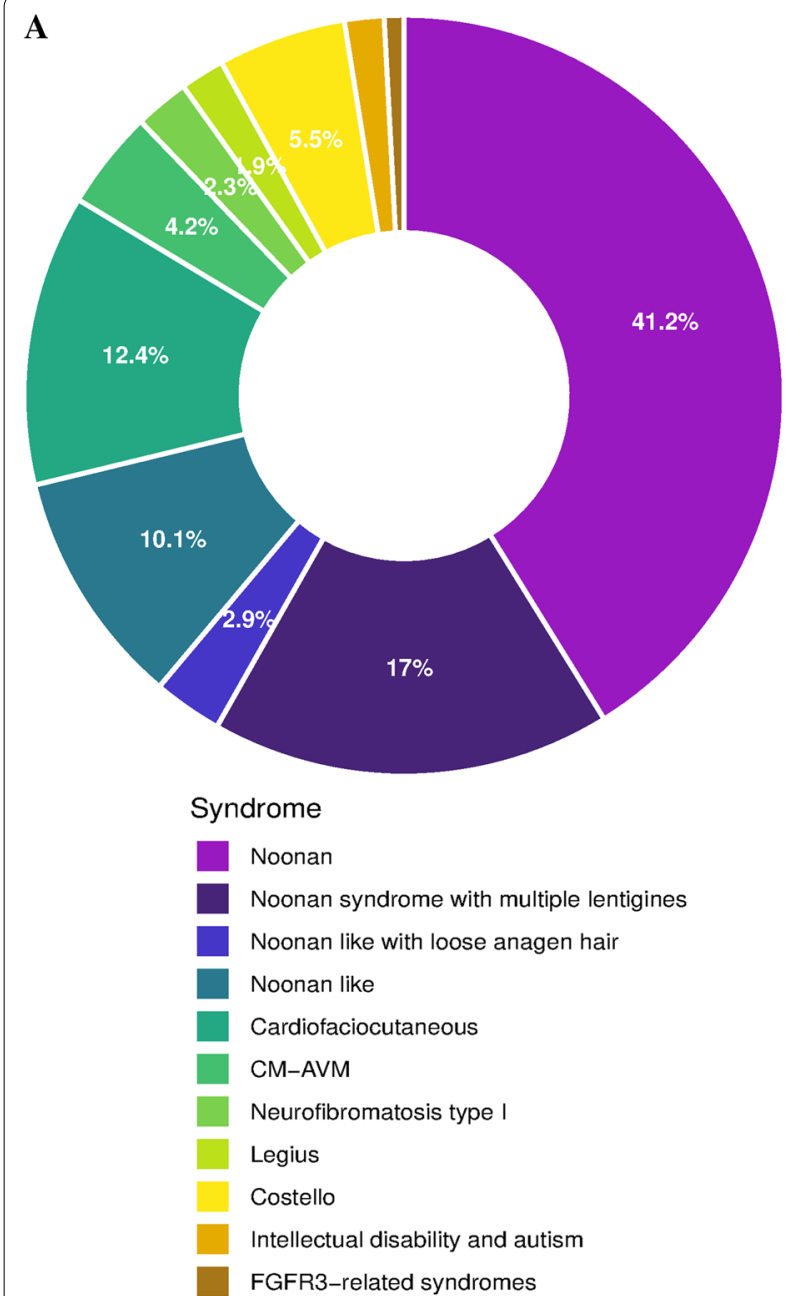

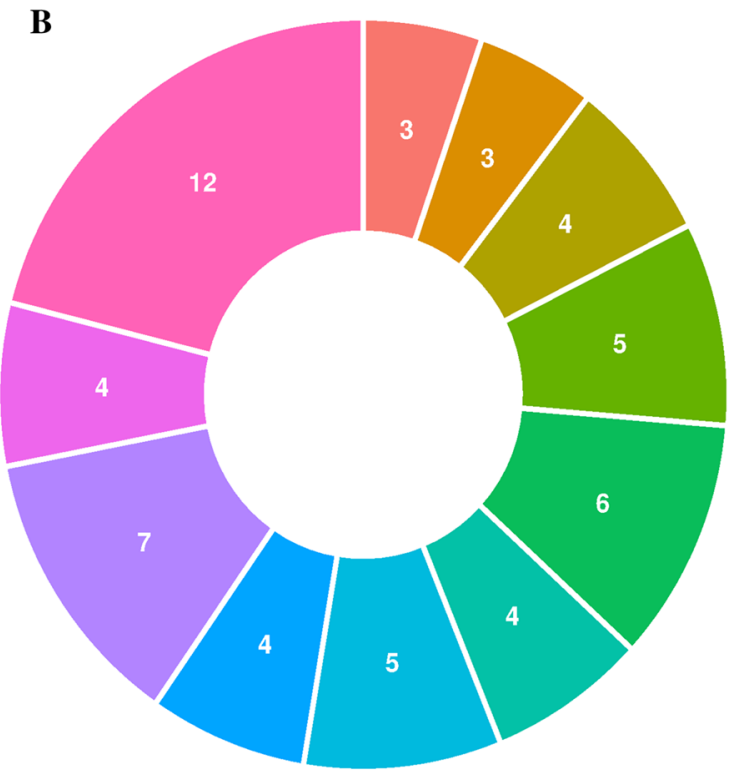

GO Biological processes

Axonogenesis (GO:0050772)

Blood coagulation (GO:0007596)

Fibroblast growth factor receptor signaling (GO:0040036)

Lipid metabolism (GO:0019216)

MAP kinase (GO:0043407) and RAS signaling (GO:0046580)

Neuron apoptosis (GO:0051402) and PNS development (GO:0007422)

Phosphatase activity (GO:0043666)

PIP3 biosynthesis (GO:0036092) and signaling (GO:0014065)

PKB signaling (GO:0043491)

Tumor necrosis factor-mediated signaling (GO:0033209)

Tyrosine phosphorylation (GO:0018108)

Fig. 3 Analysis of the interactome and their implications in each syndrome and biological processes. A Comparison of the interactome of the different RASopathies. A total of 687 proteins were analyzed. The interactome of each RASopathy is intersected with the union of all the other RASopathies interactomes. B GO Biological processes overrepresentation test results using the 432 unique protein Ids of the interactomes on the PANTHER classification system

phosphoproteins account for more than one RASopathy, including ERK1/2 (Thr202/185 and Tyr204/187), AKT1 (Thr308 and Ser473), MEK1 (Thr292) and RAF1 (Ser259), which are the most co-occurring studied proteins along the syndromes (Table 1). For most RASopathies, phosphorylation of downstream effectors was upregulated compared to the control, including but not limited to AKT, MEK1 and ERK1/ERK2.

Reported phosphoproteins with dysregulated phosphorylation in mutated RASopathy causative genes samples compared to their wild-type counterparts. The disorders include cardiofaciocutaneous (CFC), Costello syndrome (CS), juvenile myelomonocytic leukemia (JMML), Legius syndrome (LS), neurofibromatosis type 1 (NF1), Noonan syndrome (NS), Noonan syndrome-like (NSL), Noonan syndrome-like with loose anagen hair (NSLSH) and Noonan syndrome with multiple lentigines (NSML). More information about the altered phosphosite, model organism and corresponding reference can be found in Additional file $4 . \mathrm{Nd}$ stands for not determined.

The most studied syndromes are NS and NSML, thanks to the availability of phosphoproteomics data. In NS the average fold change in upregulation is 2.61 and in downregulation 0.29 , the highest fold change corresponds to PZR:Y241 (7.72) and the lowest to PTPN11:Y63 (0.02) with nearly a complete depletion of phosphorylation. In NSML the average fold change for upregulation is 2.29 and for downregulation 0.80 , the highest value also corresponds to PZR:Y263 (6.7) whereas the lowest corresponds to PDGFR (0.02). These values demonstrate 


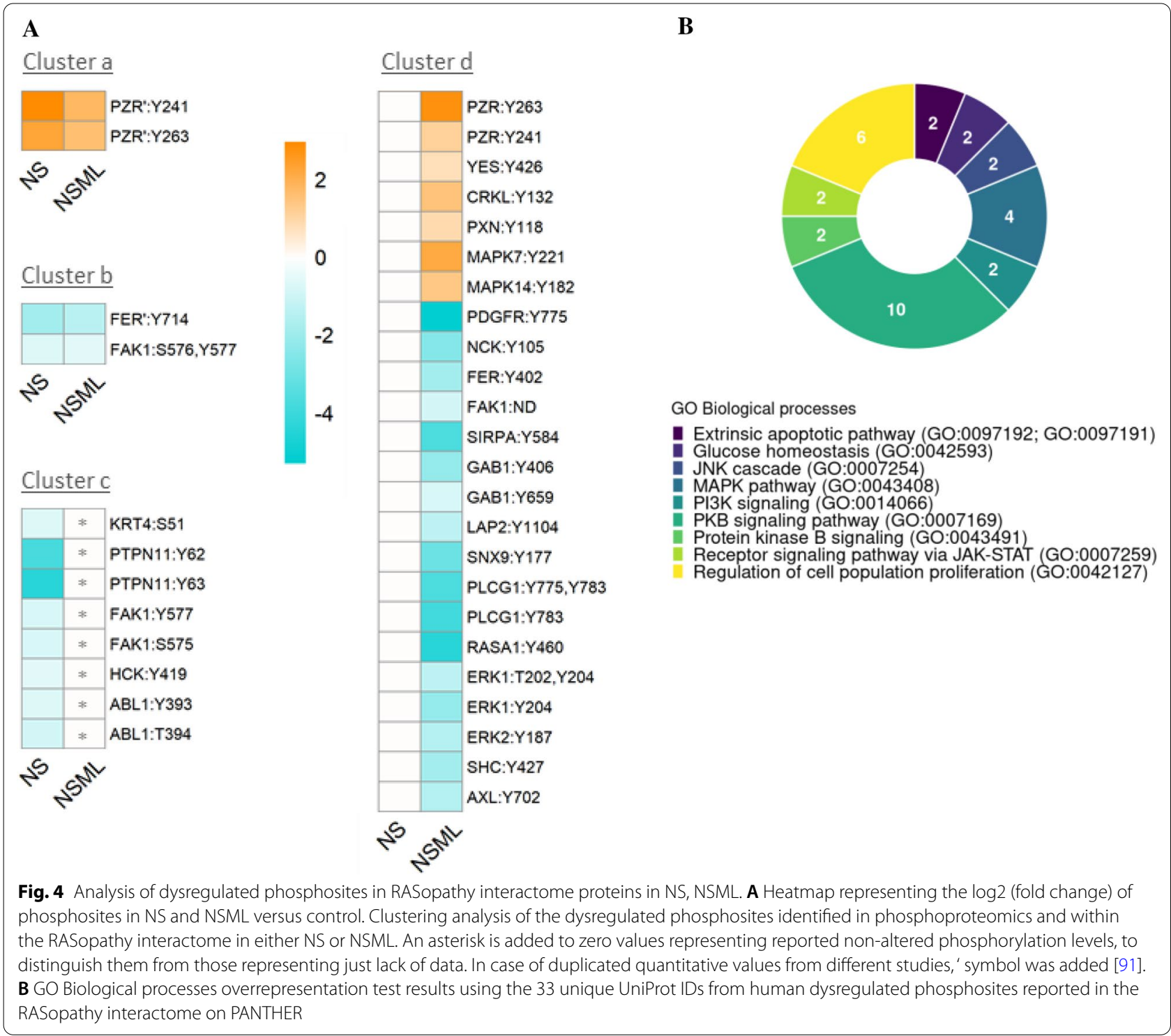

Table 1 Dysregulated downstream effectors in RASopathies based on immunoblotting

\begin{tabular}{lll}
\hline RASopathy & Up & Down \\
\hline CFC & AKT1 ERK1 ERK2 & AKT1 ERK1 ERK2 VEGFR2 \\
CS & AKT1 ERK1 ERK2 P53 RAF1 & nd \\
JMML & ERK1 ERK2 STAT5A & nd \\
LS & ERK1 ERK2 & RAF1 \\
NF1 & ERK1 ERK2 Synapsin-1 & DPYSL2 \\
NS & AKT1 BRAF ERK1 ERK2 FAK1 FER GSK-3a IGF1R INSR JNK1 MEK1 MPZL1 & ANT1 GluN2B MEK1 RAF1 \\
& P70S6K1 PECA1 RAF1 SHPS1 STAT5 VEGFR2 & nd \\
NSL & P90RSK3 S6K-alpha-1 S6K-alpha-2 & ERK1 RAF1 \\
NSLSH & nd & ERK1 ERK2 LKC MEK1 \\
NSML & AKT1 BRAF CAV2 EGFR ERK1 ERK2 FAK1 FER GSK-3a IGF1R INSR JNK1 MEK1 & P70S6K1 RAF1 Vinculin \\
& MPZL1 P70S6K1 PECA1 RAF1 SHPS1 STAT3 Tuberin &
\end{tabular}


quantitively a strong dysregulation in phosphorylation. Figure 4 shows a comparison of quantitative values available for NS and NSML, that fulfil a threshold of 1.5 in both downregulation and upregulation events. Clustering analysis of the dysregulated phosphosites identified in phosphoproteomics and within the RASopathy interactome in either NS or NSML (Fig. 4A), results in a first cluster of 2 phosphosites (cluster a) that are upregulated both in NS and NSML. A second cluster of 2 phosphosites downregulated in both NS and NSML. Interestingly, there is a number of phosphosites found dysregulated in one syndrome but not in the other. Cluster c comprises phosphosites that are dysregulated in NS but not in NSML, while cluster d shows phosphosites dysregulated in NSML and not in NS. From the phosphoproteomic analysis done in NS and NSML, a total of 4 proteins in NS (CRKL, PZR, MAPK7 and MAPK14) and 1 in NSML (PZR) have a fold change greater than 2. On the other hand, 14 proteins in NS (AXL, LAP2, ERK1, ERK2, FER, GAB1, NCK, PDGFR, PLCG1, RASA1, SHC, SIRPA, SNX9 and PTPN11) and 1 in NSML (FER) have a fold change smaller than 0.5 in disease versus control. In Additional file 5, more details on the 37 dysregulated phosphoproteins within the interactome are annotated from UniProt, including gene and protein name, UniProt ID and protein function. Interestingly, dysregulation of four RASopathy proteins including BRAF, MEK1, PTPN11 and RAF1 happened to be similar in both NS and NSML. The two phosphosites in BRAF are upregulated in NS and NSML. RAF1 contains three upregulated phosphosites and one downregulated in both syndromes. PTPN11 contains a downregulated phosphosite in both NS and NSML, whereas two other residues are differentially phosphorylated. Residue Y62 in PTPN11 is downregulated in NS and upregulated in NSML, whereas Y63 is downregulated in NS but it was not altered in NSML. MEK1 is upregulated in phosphosite T292 in NS, while in NSML the regulation varies depending on the causative mutation.

\section{Analysis of phosphosite occurrence in RASopathy proteins} Studies of the phosphoproteome in RASopathies are scarce, making difficult to evaluate how phosphorylation affects proteins. In order to have an overview of phosphorylation sites in RASopathy proteins, we used Phosphosite database to consider all documented phosphosites rather than only those with studied dysregulation. We analyzed the phosphosites for the 27 RASopathy proteins and their cognate syndromes. Information relies on low-throughput analysis (a total of 1041, 5.6\%) and high-throughput analysis (17,656, 94.4\%). Using this information, our results show that all RASopathies are associated to at least one phosphoprotein (Fig. 5). NS, with 13 proteins, contains the highest number of RASopathy proteins susceptible of phosphorylation, followed by NFNS ( 5 proteins) and JMML ( 5 proteins). Interestingly, all RASopathy proteins have residues potentially subjected to regulation by phosphorylation. BRAF, CBL, NF1, PTPN11, RAF1, SOS1 and SOS2 contain at least 20 phosphosites each, and they account for 326 of the

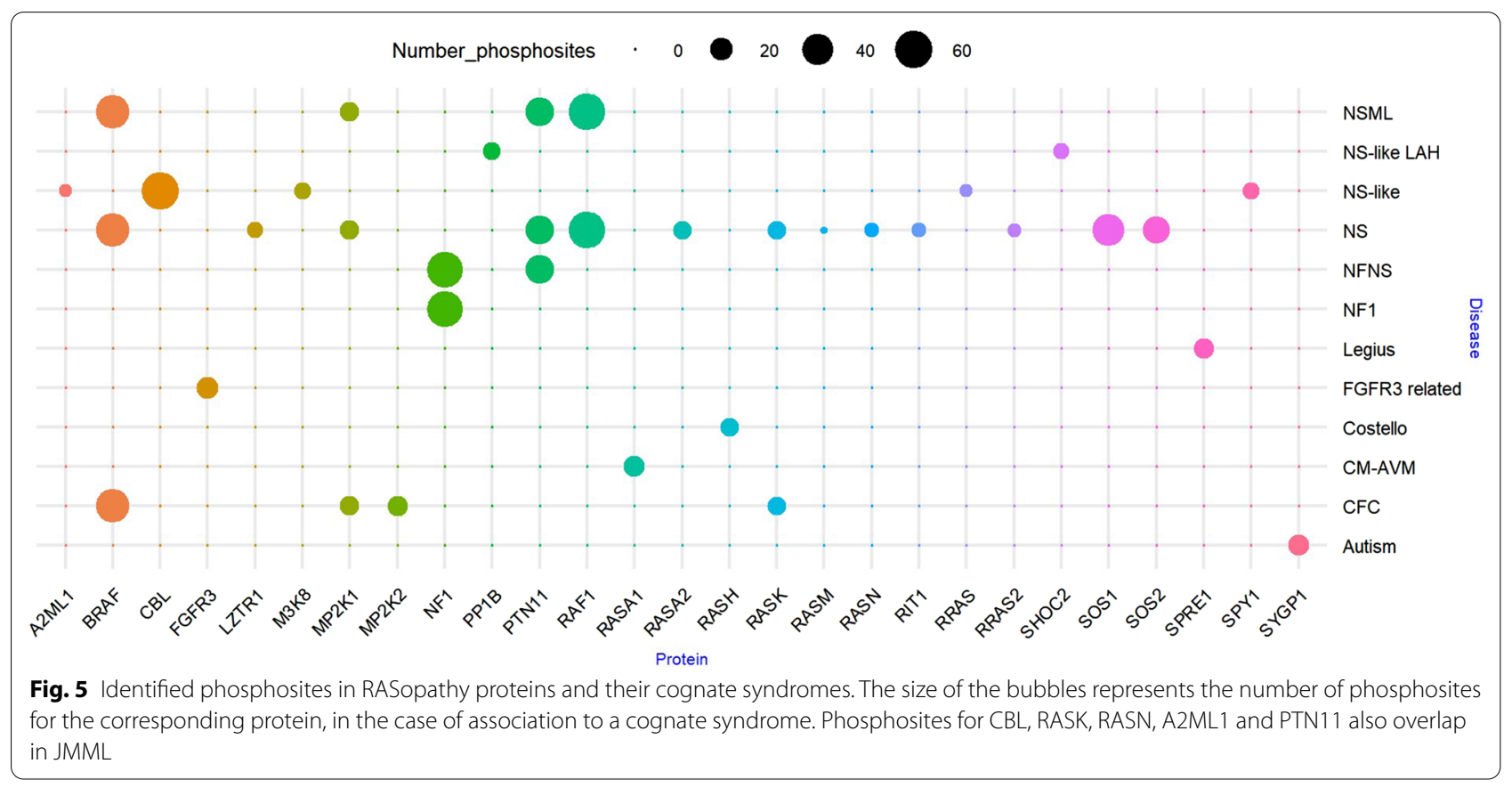


phosphosites identified in RASopathy proteins (61\% of the total). The rest of phosphosites (210) are distributed between the other 20 RASopathy proteins.

\section{Discussion}

In this study we provide a global comprehensive picture of phosphoproteome remodeling in RASopathies, including but not limited to the most up-to-date information regarding the genes that cause the RASopathies. 5 (ANKRD11, MEF2C, SRCAP, SHOX and KAT6B) out of the initial 32 proteins were excluded from further analysis based on two factors: no direct association with RAS/MAPK signaling pathway and having an interactome with a protein-protein association overlap with the rest of the RASopathy's interactomes below $16 \%$. A2ML1 was not excluded because according to our results A2ML1 interactome has a protein-protein association overlap with the rest of the RASopathy's interactomes above $25 \%$, which is even higher than the one obtained for other RASopathy proteins. FGFR3 directly interacts with RAS, and our results suggest that $24 \%$ of its interactome is shared with other RASopathy proteins. This $24 \%$ is higher than the one observed for other RASopathy proteins, including but not limited to PPP1CB, and similar to NF1. FGFR3 was considered responsible for mosaic RASopathies [73], but has not been included in any RASopathy protein panel yet in clinical studies. FGFR3 has been found to influence the RAS/MAPK signaling pathway in many studies. FGFR3 mutations are frequent in superficial urothelial cell carcinoma (UCC) as oncogenic activation of FGFR3 is predicted to result in stimulation of the MAPK pathway [97]. MIP-1 $\alpha$ (CCL3) is a downstream target of FGFR3 and RAS-MAPK signaling in multiple myeloma [98]. In hematopoietic cells, FGFR3 activates RSK2 to mediate activation of the MEK/ ERK pathway [99]. Mutations in FGFR3 and PIK3CA, singly or combined with RAS and AKT1, are associated with AKT but not with MAPK pathway activation in urothelial bladder cancer [100]. However, in another study it was found that enhanced activation of FGFR3 is linked to Ras and MAPK activation; in particular the authors described a novel FGFR3/Ras mediated mechanism for acquired-resistance to B-RAF inhibition [101]. RAS and FGFR3 mutations in urothelial carcinoma are mutually exclusive and non-overlapping events which reflect activation of oncogenic pathways through different elements. Also, papillary cancers typically exhibit activation of the MAPK pathway, as a consequence of oncogenic mutations in FGFR3 or RAS genes [102, 103]. Forced expression of FGFR3 mutants in NIH-3T3 cells resulted in cellular transformation and mitogen-activated protein kinase (MAPK) activation, resembling the transfection effects observed with activated HRAS [104, 105].
Activated FGFR3 seemed to be linked to RAS through adaptor proteins (that is, growth factor receptor-bound protein 2 (GRB2) - son of seven less (SOS) complexes) that are common to the RTK activation pathway [102]. These strong evidences of FGFR3 implications in the RAS/MAPK signaling pathway along with our in silico results of the interactome, let us suggest that FGFR3 disorders (thanatophoric dysplasia, achondroplasia, and hypochondroplasia) may be included among the RASopathies. On the other hand, KAT6B has no direct RAS interaction, poor direct association with RAS/MAPK signaling pathway with just one study so far [52] and its interactome is not associated at all with any other RASopathy protein. A translocation breakpoint 10q22.3 in a clinically diagnosed NS individual identified disruption of the KAT6B gene and hyperactivated MAPK signaling in humans and mice [52]. In particular, they found that functional studies using a patient-derived lymphoblastoid cell line causing KAT6B haploinsufficiency demonstrated an increase of RAS/MAPK pathway activity. Therefore, the authors postulated that altered expression of multiple genes associated with RAS/MAPK pathway regulation may be responsible for the increase in pathway activation and the NS-like phenotype [52]. However, that correlation has not been confirmed with more research so far. In a more recent study of a de novo heterozygous variant within exon 16 of $K A T 6 B$ that was detected in a 7-months-old Chinese female infant, the patient presented symptoms of short stature, global developmental delay, and clinical features consistent with blepharophimosis mental retardation syndromes (SBBYSS, also called Ohdo syndrome) [106]. From a clinical point of view, the KAT6B phenotypic spectrum is broad and naming of the KAT6B-related disorders has been problematic, and suggested that considering this whole group as 'KAT6B spectrum disorders' may be more helpful [107]. As expected, RAS proteins are the ones with the highest number of associations, although RASopathies related to SPRED1, MEK1/2, PTPN11, FGFR3 and SPRY1 may regulate RAS signaling differently, affecting primarily the classical RAS versus RRAS signaling.

We believe that further analysis is needed to determine the biological roles of the master nodes that we have identified in the RASopathy interactome. The functional characterization of these 12 nodes (AKT1, HRAS, PIK3R1, SRC, SOS, GRB2, CDC42, NRAS, SHC1, PPP2CA, BDNF and JNK1) may uncover implications and common patterns on the RASopathies signaling pathways, and their suitability as druggable targets. AKT is involved in many processes, including metabolism, proliferation, cell survival, growth and angiogenesis [108-111]. HRAS mutations are known to cause Costello syndrome $[8,11,59]$. Phosphatidylinositol 3-kinase plays 
an important role in the metabolic actions of insulin, and a mutation in this gene has been associated with insulin resistance [112]. SRC proto-oncogene may play a role in the regulation of embryonic development and cell growth [113]. GRB2 provides a critical link between cell surface growth factor receptors and the Ras signaling pathway $[114,115]$. Cell division cycle 42 (CDC42) regulates signaling pathways that control diverse cellular functions including cell morphology, migration, endocytosis and cell cycle progression [116-118]. Interestingly, some of these nodes, such as SHC1:(SHC1:Y427), AKT1 (S473, T308) and JNK1 (T183, Y185) are also subjected to dysregulated phosphorylation according to our phosphoproteomic analysis.

Many of the signaling cascades associated to the RAS/ MAPK pathway imply phosphorylation and dephosphorylation of proteins [5], and our results suggest that phosphoproteome remodeling in RASopathies is strongly relevant. The study of phosphosites is based on residues present in human and non-human model organisms that are extrapolated to the human sequences, so that dysregulated phosphosites may vary in human models and must be confirmed. A high proportion of the interactome (around $72 \%$ ) are phosphoproteins, when compared to a $10 \%$ accepted value of phosphoproteins in the cytoplasm [89]. Further, all RASopathy proteins contain annotated phosphosites. Also, the gene ontology analysis of the RASopathy interactome and their dysregulated phosphoproteins shows mainly phosphorylation-related processes highlighting the PKB and MAPK pathways. Previous phosphoproteomics studies in RASopathies have revealed dysregulated phosphoproteins. Our results highlight several phosphoproteins dysregulated in NS, NSML and NF1 syndromes. The impact of a particular NS or NSML associated variant on downstream targets will depend first on whether the mutated RASopathy gene is linked particularly to NS (LZTR1, MRAS, NRAS, RASA2, RIT1, RRAS2, SOS1, SOS2) or both NS and NSML (BRAF, MEK1, PTPN11, RAF1). Second, mutations within the same causative gene linked to both NS and NSML may or may not have a different impact on downstream targets. Phosphoproteomic studies suggest that a higher proportion of phosphosites is upregulated (147 versus 47 downregulated), whereas immunoblotting suggest that most studied downstream effectors are upregulated, including but not limited to AKT1, BRAF, ERK, FAK, JNK, MEK and RAF. However, in some studies MEK and RAF have been also found downregulated in both syndromes. The relative variance in symptoms between RASopathies caused by activating signaling components in NS and NSML may suggest that there are different mechanisms at play. Systematic investigation of mutation strength across other pathway components rather than RAS, ERK or AKT may yield further insights into disease etiology. Subsequent studies on candidates highlighted by phosphoproteomics, as PZR protein in NS and NSML, have been already proved useful to explain crucial pathophysiological events, such as hypertrophic cardiomyopathy and cardiac fibrosis in NSML [119]. Phosphorylation of the RASopathy proteins RAF1 [86], PTPN11 [91, 92], and BRAF [94] is altered in NS and NSML due to mutations in their corresponding genes, whereas RASA1 altered phosphorylation is associated to mutant SHP2 models [92] and not to its own mutation. The most upregulated phosphoproteins from the RASopathy interactome in NS and NSML, except for CRKL, have already been proposed as key players in these syndromes, namely PZR [90] and Fer kinase [91]. Similarly, downregulated phosphorylation levels of DPLY2 in NF1 have been well studied in neuronal differentiation [93]. Remarkably, contradictory values for identical phosphosites between different studies is an intriguing reason to further evaluate.

Phosphorylation events in the RASopathy interactome remain largely unknown. Dysregulated phosphoproteins studies only reported data for NF1 [85, 89], NS [86, 90, 91, 94] and NSML [90, 91]. For NS and NSML, mass spectrometry screenings and immunoblots were carried out, but in the case of NF1, mostly low-throughput studies have been performed, targeting only a few proteins $[85,93]$. To overcome this lack of information, we aimed to identify potential candidates for phosphoproteomics studies. BRAF phosphorylation is dysregulated both in NS and NSML. The involvement of BRAF in CFC based on genomics studies $[8,9,11,14,21,23,60]$ converts it into an appealing candidate for phosphoproteomic studies. Likewise, RASA1 phosphorylation may be important in CM-AVM [69-71] and PTPN11 in NS, NFNS [8-12] or JMML [42-44]. Other proteins may be good candidates for phosphoproteomic analysis considering their assignation to several syndromes and their high number of phosphosites including SRCAP, A2ML1, ANKRD11, NF1, SOS1 or SOS2.

Noteworthy, most phosphosites in RASopathy proteins are reported on high-throughput mass spectrometry analysis. Protocols rely on different enrichment methods for phosphoproteins (once trypsinization, S-alkylation and reduction are performed). Nano-LC-MS/MS with reversed phase columns efficiently detects phosphopeptides and the modified amino acid, although occasionally this information is limited. Strategies of isobaric labelling (TMT, iTRAQ, SILAC) offer relative quantification of phosphorylated forms or, at least, qualitative information. For instance, the iTRAQ quantifications on SHP2 mutants [90-92] and immunoprecipitated BRAF phosphomapping [94] for NS and NSML, or SILAC 
strategies in NF1-null cells [89]. On the other hand, lowthroughput analyses include immunoblots with antibodies designed towards specific phosphoresidues in purified proteins as documented for RAF-1 [86] or CRMP-2 [93]. Commercially-available kits for western-blotting of phosphorylated proteins as ProQ-Diamond dying have also been used [93], although information of the phosphoresidue must be obtained somehow else. This is the case of the two undefined phosphosites in PZR and SIRPa in our dataset. High-throughput mass spectrometry analysis broadens, with its sensitivity limitations in the pmol range, to the examination of the whole phosphoproteome, whereas immunoblotting is limited to a few chosen proteins. Nonetheless, immunoblot analAysis offer specific and reliable information that may complement the monitorization of hundreds of proteins identified by MS strategies.

\section{Conclusions}

Herein, we provide for further studies with a comprehensive up-to-date analysis of 27 RASopathy genes involved in the RAS-MAPK pathway and their interactome, which comprises at least 432 different proteins including 12 nodes, highlighting AKT, HRAS and PIK3R1 as the top three, and involved in several biological processes directly related with the nervous system including but not limited to axonogenesis, peripheral nervous system development and neuron apoptosis.

Current state-of-the-art allows obtaining rich information based on the hypothesis that phosphoproteome remodeling is a key event in RASopathies. Accordingly, we present an integrative and comprehensive analysis of their interactome with regards to dysregulated phosphoproteins. 370 out of the 432 proteins are annotated as phosphoproteins, from which we identify a set of 37 phosphoproteins dysregulated in NF1 (3 proteins), NS (33 proteins), NSML (19 proteins), NSL (1 protein), NSLH (3 proteins), LS (2 proteins), CS (2 proteins), CFC ( 3 proteins) and JMML ( 2 proteins), some of them found in more than one syndrome. For most RASopathies, phosphorylation of downstream effectors was upregulated compared to the control, including but not limited to AKT, MEK1 and ERK1/ERK2. All RASopathies are associated to at least one phosphoprotein, in which the NS leads the number of identified phosphoproteins with 13 proteins, followed by NFNS ( 5 proteins) and JMML (5 proteins). Although just a few phosphoproteomic assays have been done in the onset of RASopathies, we encourage to outline future strategies to unveil the molecular events underlying the RASopathies using mass spectrometry approaches. This is an exciting field to widen molecular knowledge in rare diseases and even aim for translation into clinics.

\section{Methods}

Generation of a RASopathy proteins interactome

STRING (https://string-db.org/) is a database of known and predicted protein-protein interactions. The interactions include direct (physical) and indirect (functional) associations; they stem from computational prediction, from knowledge transfer between organisms, and from interactions aggregated from other (primary) databases. In order to analyze the RASopathy proteins using STRING, we first compiled an updated panel of RASopathy-related genes including 27 RASopathy genes: $A 2 M L 1, B R A F, C B L, H R A S, K A T 6 B, K R A S$, LZTR1, MAP3K8, MEK1, MEK2, MRAS, NF1, NRAS, PPP1CB, PTPN11, RAF1, RASA1, RASA2, RIT1, RRAS, RRAS2, SHOC2, SOS1, SOS2, SPRED1, SPRY1 and SYNGAP1; and 5 extra genes ANKRD11, FGFR3, MEF2C, $S H O X$ and $S R C A P$, that were previously proposed as RASopathy proteins as mentioned in the introduction. The UniProt IDs for all the above 32 proteins were submitted to STRING database under the multiple proteins search. The following basic settings were used to generate a portable network graphic: confidence for the meaning of network edges (line thickness indicates the strength of data support); active interaction sources are based on experiments and databases only; and high confidence $(0.700)$ as the minimum required interactome score. Edges represent protein-protein associations. For the generation of the RASopathy proteins interactome (Fig. 2A) in STRING "none/query proteins only" and "none" values were used for the 1st and 2nd shell, respectively. These associations are meant to be specific and meaningful (i.e. proteins jointly contribute to a shared function), although this does not necessarily mean they are physically binding each other.

\section{Generation of a RASopathy proteins and neighbors interactome}

An interactome was generated including the above 32 RASopathy proteins and their neighbors. We first downloaded all protein-protein associations for each individual RASopathy protein from STRING (using export your current network protein annotations link) and complemented with those annotated in UniProt database (under the Interaction section, which provides information on interaction(s) with other proteins or protein complexes). Data compilation yielded a total of 765 proteins (Additional file 1: Tab1), including 511 unique proteins based on UniProt IDs (Additional file 1: Tab2). Functional annotation of the 511 unique proteins was carried out using DAVID (https://david. ncifcrf.gov/). 


\section{Analysis of the main hub proteins of the interactome network}

In order to further analyze relationships within the whole interactome derived from the 32 RASopathy proteins, we used STRING to build a network of the interactions with the above list of 511 unique proteins (Additional file 1). The resulting network has a total of 8191 edges representing protein-protein associations. Then, in order to find highly connected nodes within the network, the number of edges for every single node was calculated. We focused our analysis on selected nodes that had a number of interactions greater than 4 times the average of interactions found in the network (mean $=18.4$ interactions).

\section{Dataset compilation of dysregulated phosphosites in RASopathies}

We scrutinized all previous phosphoproteomics studies carried out in RASopathies using PubMed with the following keywords: "phosphoproteomics", "phosphoproteome", "phosphorylation", "RASopathy", "Neurofibromatosis", “Noonan'”'Leopard”, “cardiofaciocutaneous", "Legius", "Costello", "autism", "capillary malformationarteriovenous malformation syndrome", "juvenile myelomonocytic leukemia", "NF1", "PTPN11", "RAF1", "MEK1”, "BRAF”, "KRAS", "MEK2", “SPRED1", HRAS "A2ML1", “CBL”, “MAP3K8”, “KAT6B”, "RRAS”, "SPRY1", “SHOC2”, "PPP1CB”, “SYNGAP1", "RASA1". Protein phosphorylation level changes associated to RASopathies were compiled from nine phosphoproteomic and twenty-seven immunoblotting studies (Additional file 4) [15, 16, 19, 21, 85-87, 89-94, 120-138]. The sample size, animal model, type of data (quantitative/qualitative) and statistical validation is also included in Additional file 4 . These phosphosites were compiled (Additional file 4) and belong to different organisms including human, monkey, rat, mouse and zebrafish. Phosphoproteins in the original organism were correlated to the orthologous human counterpart. UniProt retrieve/ID mapping tool [139] was used for mouse, rat and monkey proteins, and ZFIN [140] database was used for zebrafish proteins. The equivalent phosphosites in human were mapped by pairwise comparison of the phosphosite orthologous sequences, using the Phosphosite database [141]. Each identified dysregulated phosphosite was annotated based on the human UniProt protein name and the phosphorylated residues.

\section{Analysis of dysregulated phosphoproteins present in the RASopathy interactome}

Differential phosphorylation levels were analyzed in the RASopathy interactome. UniProt IDs from the interactome (Additional file 1) and from the dataset of dysregulated phosphosites in RASopathies (Additional file 4) were crossed. The identified proteins were selected for further analysis. Phosphorylation levels are normalized to the total abundance of each phosphoprotein, providing harmonization of the data between experimental models and organisms. Fold changes in the RASopathy versus control were used to represent dysregulation in each phosphosite, transformed to base 2 logarithm (log2 [fold change/). A threshold of 1.5 both in upregulation and downregulation was applied to filter out noise in the data. Qualitative data was processed in parallel assigning upand down-regulation based on original data. R 3.63 [142] and RStudio 1.2.5042 [143] were used to generate a heatmap representing fold changes of each phosphosite ( $R$ package pheatmap [144]). Clustering analysis was done in NS and NSML by selecting manually from quantitative data dysregulated phosphoproteins with available information for only NS syndrome, phosphoproteins equally dysregulated in both syndromes and phosphoproteins dissimilarly dysregulated in both syndromes.

The analysis of dysregulated phosphoproteins present in the RASopathy interactome presented some limitations. Different models, even when they mimic the same syndrome, may show a different response in terms of phosphorylation changes that may be driven in part, by the different experimental conditions. Therefore, experimental validation is recommended for those less studied phosphoproteins. In terms of statistical validation, some original phosphoproteomic studies [89-92] were done for screening purposes. Most immunoblots data was statistically validated including several biological replicates. These aspects are included in Additional file 4.

\section{Analysis of RASopathy proteins phosphosites}

We investigated the presence of phosphosites in the 27 confirmed RASopathy proteins using available information in the Phosphosite [141] database. All phosphosites up to available referenced works demonstrating phosphorylation of amino acids in the human sequence were included, independently of the study on their dysregulation in RASopathies (Additional file 6). Classification of the references into high-throughput and low-throughput studies was annotated, but both equally considered. Total number of phosphosites per protein with correlation to the cognate RASopathy syndrome, were represented in a bubble plot using R 3.63 [142] and RStudio 1.2.5042 [143] ( $\mathrm{R}$ package ggplot2).

\section{Gene ontology analysis and biological processes}

The 27 RASopathy proteins (Fig. 3B) and the 33 dysregulated phosphoproteins in the RASopathy interactome (Fig. 4B) were annotated for GO terms using PANTHER (http://www.pantherdb.org/) classification system tool. A statistical over-representation test using the human PANTHER GO-Slim Biological Process database was 
used. All groups were selected attending to its statistical significance (FDR value $<0.01$ ) and according to the most specific subclass on the GO hierarchy term they belong to.

\section{Limitations of the study for phosphoproteomics data}

In its conceptualization, our study compiles information from articles including different models and statistical validations assuming some limitations. MS phosphoproteomics studies were used for screening purposes [89-92], and statistics are limited since no p-value test has been performed. Qualitative data from immunoblots is validated by replication of the experiment and fullfill a p-value threshold of 0.05 . Details for each study can be consulted in Additional file 4.Therefore, we can only suggest herein the impact of phosphorylation changes in RASopathies and key phosphoproteins from a point of view of screening and based in the co-occurrence and relevance considering crossed data.

\begin{abstract}
Abbreviations
NF1: Neurofibromatosis type I; LC-MS: Liquid chromatography coupled to mass spectrometry; LS: Legius syndrome; NS: Noonan syndrome; NFNS: Neurofibromatosis-Noonan syndrome; NSL: Noonan syndrome-like; NSML: Noonan syndrome with multiple lentigines; NSLSH: Noonan syndrome-like with loose anagen hair; CS: Costello syndrome; CFC: Cardiofaciocutaneous syndrome; CM-AVM: Capillary malformation-arteriovenous malformation syndrome; JMML: Juvenile myelomonocytic leukemia; MPNST: Malignant peripheral nerve sheath tumors; GEFs: Guanine nucleotide exchange factors; GAPs: GTPase-activating proteins.
\end{abstract}

\section{Supplementary Information}

The online version contains supplementary material available at https://doi. org/10.1186/s13023-021-01934-x.

Additional file 1: Table S1. The direct interactome of the RASopathy proteins.

Additional file 2: Table S2. Overlap of the direct interactome of the RASopathy proteins.

Additional file 3: Table S3. Functional annotation clustering of the RASOpathy interactome proteins.

Additional file 4: Table S4. Dysregulated phosphoproteins in RASopathy animal models.

Additional file 5: Table S5. Dysregulated phosphorylation in the RASopathy interactome.

Additional file 6: Table S6. Phosphosites of RASopathy proteins.

\section{Acknowledgements}

Not applicable

\section{Authors' contributions}

$J \mathrm{~L}$ and JFMB conceived of the study. JL carried out the molecular genetics and interactomics studies, JFMB perform the phosphoproteomic study, OGV performed the gene ontology analysis and the analysis of the main hub proteins of the interactome. JL and JFMB wrote the original draft, JL, JFMB, OGV and $\mathrm{Ml}$ reviewed and corrected the article. All authors read and approved the final manuscript.

\section{Funding}

This research was funded by Junta de Castilla y León Health Council, grant number GRS2084/A/19 (PI: María Isidoro-García).

\section{Availability of data and materials}

The dataset(s) supporting the conclusions of this article are included within the article (and its Additional File(s)).

\section{Declarations}

Ethics approval and consent to participate

Not applicable.

\section{Consent for publication}

Not applicable.

\section{Competing interests}

The authors declare that they have no competing interests.

\section{Author details}

${ }^{1}$ Metabolic Engineering Group, Department of Microbiology and Genetics, Faculty of Biology, University of Salamanca, 37007 Salamanca, Spain. ${ }^{2}$ Bioinformatics and Functional Genomics Group, IBMCC Cancer Research Center, Campus Miguel de Unamuno, 37007 Salamanca, Spain. ${ }^{3}$ Institute for Biomedical Research of Salamanca (IBSAL), 37007 Salamanca, Spain. ${ }^{4}$ Network for Cooperative Research in Health-RETICS ARADyAL, 37007 Salamanca, Spain. ${ }^{5}$ Department of Clinical Biochemistry, University Hospital of Salamanca, 37007 Salamanca, Spain. ${ }^{6}$ Department of Medicine, University of Salamanca, 37007 Salamanca, Spain. ${ }^{7}$ Molecular Genetics of Human Diseases Group, Department of Microbiology and Genetics, Faculty of Biology, University of Salamanca, 37007 Salamanca, Spain.

Received: 29 September 2020 Accepted: 27 June 2021

Published online: 06 July 2021

\section{References}

1. Pevec U, Rozman N, Gorsek B, Kunej T. RASopathies: presentation at the genome, interactome, and phenome levels. Mol Syndromol. 2016;7:72-9.

2. Kim YE, Baek ST. Neurodevelopmental aspects of RASopathies. Mol Cells. 2019:42:441-7.

3. Simanshu DK, Nissley DV, McCormick F. RAS proteins and their regulators in human disease. Cell. 2017;170:17-33.

4. Lasho T, Patnaik MM. Juvenile myelomonocytic leukemia-a bona fide RASopathy syndrome. Best Pract Res Clin Haematol. 2020;33:101171.

5. Dard L, Bellance N, Lacombe D, Rossignol R. RAS signalling in energy metabolism and rare human diseases. Biochim Biophys Acta Bioenerg. 2018;1859:845-67. https://doi.org/10.1016/j.bbabio.2018.05.003.

6. Ratner N, Miller SJ. A RASopathy gene commonly mutated in cancer: The neurofibromatosis type 1 tumour suppressor. Nat Rev Cancer. 2015;15:290-301.

7. Brems H, Chmara M, Sahbatou M, Denayer E, Taniguchi K, Kato R, et al. Germline loss-of-function mutations in SPRED1 cause a neurofibromatosis 1-like phenotype. Nat Genet. 2007;39:1120-6.

8. Lee BH, Kim JM, Jin HY, Kim GH, Choi JH, Yoo HW. Spectrum of mutations in Noonan syndrome and their correlation with phenotypes. J Pediatr. 2011;159:1029-35. https://doi.org/10.1016/j.jpeds.2011.05.024.

9. Lepri FR, Scavelli R, Digilio MC, Gnazzo M, Grotta S, Dentici ML, et al. Diagnosis of Noonan syndrome and related disorders using target next generation sequencing. BMC Med Genet. 2014;15:1-11.

10. Pannone L, Bocchinfuso G, Flex E, Rossi C, Baldassarre G, Lissewski C, et al. Structural, functional, and clinical characterization of a novel PTPN1 1 mutation cluster underlying Noonan syndrome. Hum Mutat. 2017:38:451-9.

11. Chinton J, Huckstadt V, Moresco A, Gravina LP, Obregon MG. Clinical and molecular characterization of children with Noonan syndrome and other RASopathies in Argentina. Arch Argent Pediatr. 2019;117(5):330-7. 
12. Li X, Yao R, Tan X, Li N, Ding Y, Li J, et al. Molecular and phenotypic spectrum of Noonan syndrome in Chinese patients. Clin Genet. 2019;96:290-9. https://doi.org/10.1111/cge.13588.

13. Roberts AE, Araki T, Swanson KD, Montgomery KT, Schiripo TA, Joshi $V A$, et al. Germline gain-of-function mutations in SOS1 cause Noonan syndrome. Nat Genet. 2007;39:70-4.

14. Croonen EA, Nillesen W, Schrander C, Jongmans M, Scheffer H, Noordam C, et al. Noonan syndrome: comparing mutation-positive with mutation-negative Dutch patients. Mol Syndromol. 2013:4:227-34.

15. Pandit B, Sarkozy A, Pennacchio LA, Carta C, Oishi K, Martinelli S, et al. Gain-of-function RAF1 mutations cause Noonan and LEOPARD syndromes with hypertrophic cardiomyopathy. Nat Genet. 2007:39:1007-12.

16. Razzaque MA, Nishizawa T, Komoike Y, Yagi H, Furutani M, Amo R, et al. Germline gain-of-function mutations in RAF1 cause Noonan syndrome. Nat Genet. 2007;39:1013-7.

17. Harms FL, Alawi M, Amor DJ, Tan TY, Cuturilo G, Lissewski C, et al. The novel RAF1 mutation p. (Gly361Ala) located outside the kinase domain of the CR3 region in two patients with Noonan syndrome, including one with a rare brain tumor. Am J Med Genet Part A. 2018;176:470-6.

18. Aoki Y, Niihori T, Banjo T, Okamoto N, Mizuno S, Kurosawa K, et al. Gainof-function mutations in RIT1 cause noonan syndrome, a RAS/MAPK pathway syndrome. Am J Hum Genet. 2013;93:173-80. https://doi.org/ 10.1016/j.ajhg.2013.05.021.

19. Chen J-L, Zhu X, Zhao T-L, Wang J, Yang Y-F, Tan Z-P. Rare copy number variations containing genes involved in RASopathies: deletion of SHOC2 and duplication of PTPN11. Mol Cytogenet. 2014;7:28. https:// doi.org/10.1186/1755-8166-7-28.

20. Koenighofer M, Hung CY, Mccauley JL, Dallman J, Back EJ, Mihalek I, et al. Mutations in RIT1 cause Noonan syndrome-additional functional evidence and expanding the clinical phenotype. Clin Genet. 2016;89:359-66.

21. Sarkozy A, Carta C, Moretti S, Zampino G, Digilio MC, Pantaleoni F, et al. Germline BRAF mutations in noonan, LEOPARD, and cardiofaciocutaneous syndromes: molecular diversity and associated phenotypic spectrum. Hum Mutat. 2009;30:695-702. https://doi.org/10.1002/humu. 20955.

22. Carta C, Pantaleoni F, Bocchinfuso G, Stella L, Vasta I, Sarkozy A, et al. Germline missense mutations affecting KRAS isoform $B$ are associated with a severe Noonan syndrome phenotype. Am J Hum Genet. 2006;79:129-35

23. Nava C, Hanna N, Michot C, Pereira S, Pouvreau N, Niihori T, et al. Cardiofacio-cutaneous and Noonan syndromes due to mutations in the RAS/ MAPK signalling pathway: genotype-phenotype relationships and overlap with Costello syndrome. J Med Genet. 2007;44:763-71.

24. Yamamoto GL, Aguena M, Gos M, Hung C, Pilch J, Fahiminiya S, et al. Rare variants in SOS2 and LZTR1 are associated with Noonan syndrome. J Med Genet. 2015;52:413-21.

25. El Bouchikhi I, Belhassan K, Moufid FZ, Iraqui Houssaini M, Bouguenouch L, Samri I, et al. Noonan syndrome-causing genes: molecular update and an assessment of the mutation rate. Int J Pediatr Adolesc Med. 2016;3:133-42. https://doi.org/10.1016/j.ijpam.2016.06.003.

26. Tidyman WE, Rauen KA. Expansion of the RASopathies. Curr Genet Med Rep. 2016:4:57-64.

27. Chinton J, Huckstadt V, Mucciolo M, Lepri F, Novelli A, Gravina LP, et al. Providing more evidence on LZTR1 variants in Noonan syndrome patients. Am J Med Genet Part A. 2020;182:409-14. https://doi.org/10. 1002/ajmg.a.61445.

28. Pierpont El, Semrud-Clikeman M, Pierpont ME. Variability in clinical and neuropsychological features of individuals with MAP2K1 mutations. Am J Med Genet Part A. 2017;173:452-9.

29. Chen PC, Yin J, Yu HW, Yuan T, Fernandez M, Yung CK, et al. Nextgeneration sequencing identifies rare variants associated with Noonan syndrome. Proc Natl Acad Sci USA. 2014;111:11473-8.

30. Higgins EM, Bos JM, Mason-Suares H, Tester DJ, Ackerman JP, MacRae CA, et al. Elucidation of MRAS-mediated Noonan syndrome with cardiac hypertrophy. JCI Insight. 2017;2:1-17.

31. Suzuki H, Takenouchi T, Uehara T, Takasago S, Ihara S, Yoshihashi H, et al. Severe Noonan syndrome phenotype associated with a germline Q71R MRAS variant: a recurrent substitution in RAS homologs in various cancers. Am J Med Genet Part A. 2019. https://doi.org/10.1002/ajmg.a. 61261.

32. Motta M, Sagi-Dain L, Krumbach OHF, Hahn A, Peleg A, German A, et al. Activating MRAS mutations cause Noonan syndrome associated with hypertrophic cardiomyopathy. Hum Mol Genet. 2019. https://doi.org/ 10.1093/hmg/ddz108/5492387.

33. Cirstea IC, Kutsche K, Dvorsky R, Gremer L, Carta C, Horn D, et al. A restricted spectrum of NRAS mutations causes Noonan syndrome. Nat Genet. 2010:42:27-9.

34. Kraoua L, Journel H, Bonnet P, Amiel J, Pouvreau N, Baumann C, et al. Constitutional NRAS mutations are rare among patients with Noonan syndrome or juvenile myelomonocytic leukemia. Am J Med Genet Part A. 2012;158A:2407-11.

35. Ekvall S, Wilbe M, Dahlgren J, Legius E, van Haeringen A, Westphal O, et al. Mutation in NRAS in familial Noonan syndrome - case report and review of the literature. BMC Med Genet. 2015. https://doi.org/10.1186/ s12881-015-0239-1.

36. Cirenajwis $H$, Lauss $M$, Ekedahl $H$, Törngren $T$, Kvist $A$, Saal LH, et al. NF1 -mutated melanoma tumors harbor distinct clinical and biological characteristics. Mol Oncol. 2017;11:438-51. https://doi.org/10.1002/ 1878-0261.12050.

37. Capri Y, Flex E, Krumbach OHF, Carpentieri G, Cecchetti S, Lißewski C, et al. Activating mutations of RRAS2 are a rare cause of Noonan syndrome. Am J Hum Genet. 2019;104:1223-32.

38. Niihori T, Nagai K, Fujita A, Ohashi H, Okamoto N, Okada S, et al. Germline-activating RRAS2 mutations cause Noonan syndrome. Am J Hum Genet Cell Press. 2019;104:1233-40.

39. Ekvall S, Sjörs K, Jonzon A, Vihinen M, Annerén G, Bondeson M-L. Novel association of neurofibromatosis type 1-causing mutations in families with neurofibromatosis-Noonan syndrome. Am J Med Genet Part A. 2014;164:579-87. https://doi.org/10.1002/ajmg.a.36313.

40. Stiller C, Chessells J, Fitchett M. Neurofibromatosis and childhood leukaemia/lymphoma: a population-based UKCCSG study. Br J Cancer. 1994;70:969-72.

41. Arber DA, Orazi A, Hasserjian R, et al. The 2016 revision to the World Health Organization classification of myeloid neoplasms and acute leukemia. Blood. 2016;127(20):2391-405 (Blood. 2016;128:462-3).

42. Shannon KM, O'Connell P, Martin GA, Paderanga D, Olson K, Dinndorf $P$, et al. Loss of the normal NF1 allele from the bone marrow of children with type 1 neurofibromatosis and malignant myeloid disorders. N Engl J Med. 1994;330:597-601. https://doi.org/10.1056/NEJM19940303330 0903.

43. Niemeyer CM, Flotho C. Juvenile myelomonocytic leukemia: who's the driver at the wheel? Blood. 2019;133:1060-70.

44. Hamdy N, Bokhary H, Elsayed A, Hozayn W, Soliman S, Salem S, et al. RAS pathway mutation patterns in patients with juvenile myelomonocytic leukemia: a developing country single-center experience. Clin Lymphoma Myeloma Leuk. 2020;20:e368-74.

45. Borkhardt A, Bojesen S, Haas OA, Fuchs U, Bartelheimer D, Loncarevic IF, et al. The human GRAF gene is fused to MLL in a unique $t(5 ; 11)$ (q31;q23) and both alleles are disrupted in three cases of myelodysplastic syndrome/acute myeloid leukemia with a deletion 5q. Proc Natl Acad Sci. 2000;97:9168-73. https://doi.org/10.1073/pnas.150079597.

46. Caye A, Strullu M, Guidez F, Cassinat B, Gazal S, Fenneteau O, et al. Juvenile myelomonocytic leukemia displays mutations in components of the RAS pathway and the PRC2 network. Nat Genet. 2015;47:1334-40.

47. Sakaguchi H, Okuno Y, Muramatsu H, Yoshida K, Shiraishi Y, Takahashi M, et al. Exome sequencing identifies secondary mutations of SETBP1 and JAK3 in juvenile myelomonocytic leukemia. Nat Genet. 2013;45:937-41.

48. Wakamatsu M, Okuno Y, Murakami N, Miwata S, Kitazawa H, Narita K, et al. Detection of subclonal SETBP1 and JAK3 mutations in juvenile myelomonocytic leukemia using droplet digital PCR. Leukemia. 2020;35:259-63.

49. Morerio C. HCMOGT-1 is a novel fusion partner to PDGFRB in Juvenile myelomonocytic leukemia with $\mathrm{t}(5 ; 17)(\mathrm{q} 33 ; \mathrm{p} 11.2)$. Cancer Res. 2004:64:2649-51. https://doi.org/10.1158/0008-5472.CAN-03-4026.

50. Vissers LELM, Bonetti M, Paardekooper Overman J, Nillesen WM, Frints SGM, De Ligt J, et al. Heterozygous germline mutations in A2ML1 are associated with a disorder clinically related to Noonan syndrome. Eur J Hum Genet. 2015:23:317-24. 
51. Edwards JJ, Martinelli S, Pannone L, Lo IFM, Shi L, Edelmann L, et al. A PTPN11 allele encoding a catalytically impaired SHP2 protein in a patient with a Noonan syndrome phenotype. Am J Med Genet Part A. 2014;164:2351-5.

52. Kraft M, Cirstea IC, Voss AK, Thomas T, Goehring I, Sheikh BN, et al. Disruption of the histone acetyltransferase MYST4 leads to a noonan syndrome-like phenotype and hyperactivated MAPK signaling in humans and mice. J Clin Investig. 2011;121:3479-91.

53. Flex E, Jaiswal M, Pantaleoni F, Martinelli S, Strullu M, Fansa EK, et al. Activating mutations in RRAS underlie a phenotype within the RASopathy spectrum and contribute to leukaemogenesis. Hum Mol Genet. 2014;23:4315-27.

54. Nishi E, Mizuno S, Nanjo Y, Niihori T, Fukushima Y, Matsubara Y, et al. A novel heterozygous MAP2K1 mutation in a patient with Noonan syndrome with multiple lentigines. Am J Med Genet Part A. 2015;167:407-11.

55. Cordeddu V, Di SE, Pennacchio LA, Ma A, Fodale V, Cecchetti S, et al. Mutation in SHOC2 promotes aberrant protein $\mathrm{N}$-myristoylation and underlies Noonan-like syndrome with loose anagen hair. Nat Genet. 2009:41:1022-6.

56. Couser NL, Keelean-Fuller D, Davenport ML, Haverfield E, Masood MM, Henin M, et al. Cleft palate and hypopituitarism in a patient with Noonan-like syndrome with loose anagen hair-1. Am J Med Genet Part A. 2018:176:2024-7. https://doi.org/10.1002/ajmg.a.40432.

57. Gripp KW, Aldinger KA, Bennett JT, Baker L, Tusi J, Powell-Hamilton $\mathrm{N}$, et al. A novel rasopathy caused by recurrent de novo missense mutations in PPP1CB closely resembles Noonan syndrome with loose anagen hair. Am J Med Genet Part A. 2016;170:2237-47. https://doi.org/ 10.1002/ajmg.a.37781

58. Bertola D, Yamamoto G, Buscarilli M, Jorge A, Passos-Bueno MR, Kim C. The recurrent PPP1CB mutation p.Pro49Arg in an additional Noonanlike syndrome individual: broadening the clinical phenotype. Am J Med Genet Part A. 2017;173:824-8. https://doi.org/10.1002/ajmg.a.38070.

59. Aoki Y, Niihori T, Kawame H, Kurosawa K, Ohashi H, Tanaka Y, et al. Germline mutations in HRAS proto-oncogene cause Costello syndrome. Nat Genet. 2005;37:1038-40.

60. Niihori T, Aoki Y, Narumi Y, Neri G, Cavé H, Verloes A, et al. Germline KRAS and BRAF mutations in cardio-facio-cutaneous syndrome. Nat Genet. 2006;38:294-6.

61. Gripp KW, Lin AE, Nicholson L, Allen W, Cramer A, Jones $K L_{\text {, }}$ et al. Further delineation of the phenotype resulting from BRAF or MEK1 germline mutations helps differentiate cardio-facio-cutaneous syndrome from Costello syndrome. Am J Med Genet Part A. 2007;143A:1472-80.

62. Rauen KA, Tidyman WE, Estep AL, Sampath S, Peltier HM, Bale SJ, et al. Molecular and functional analysis of a novel MEK2 mutation in cardiofacio-cutaneous syndrome: transmission through four generations. Am J Med Genet Part A. 2010;152A:807-14. https://doi.org/10.1002/ajmg.a. 33342.

63. Gos M, Smigiel R, Kaczan T, Landowska A, Abramowicz A, Sasiadek M, et al. MAP2K2 mutation as a cause of cardio-facio-cutaneous syndrome in an infant with a severe and fatal course of the disease. Am J Med Genet Part A. 2018;176:1670-4.

64. Sanri A, Gurkan H, Demir S. Cardiofaciocutaneous syndrome phenotype in a case with de novo KRAS pathogenic variant. Mol Syndromol. 2020;10:344-7.

65. Hamdan FF, Gauthier J, Spiegelman D, Noreau A, Yang Y, Pellerin S, et al. Mutations in SYNGAP1 in autosomal nonsyndromic mental retardation. N Engl J Med. 2009;360:599-605.

66. Jimenez-Gomez A, Niu S, Andujar-Perez F, McQuade EA, Balasa A, Huss $D$, et al. Phenotypic characterization of individuals with SYNGAP1 pathogenic variants reveals a potential correlation between posterior dominant rhythm and developmental progression. J Neurodev Disord. 2019;11:1-11

67. Weldon M, Kilinc M, Lloyd Holder J, Rumbaugh G. The first international conference on SYNGAP1-related brain disorders: a stakeholder meeting of families, researchers, clinicians, and regulators. J Neurodev Disord. 2018;10:1-6.

68. Campbell JD, Alexandrov A, Kim J, Wala J, Berger AH, Pedamallu CS, et al. Distinct patterns of somatic genome alterations in lung adenocarcinomas and squamous cell carcinomas. Nat Genet. 2016;48:607-16.
69. Eerola I, Boon LM, Mulliken JB, Burrows PE, Dompmartin A, Watanabe S, et al. Capillary malformation-arteriovenous malformation, a new clinical and genetic disorder caused by RASA1 mutations. Am J Hum Genet. 2003;73:1240-9.

70. Revencu N, Boon LM, Mendola A, Cordisco MR, Dubois J, Clapuyt $P$, et al. RASA1 mutations and associated phenotypes in 68 families with capillary malformation-arteriovenous malformation. Hum Mutat 2013;34:1632-41. https://doi.org/10.1002/humu.22431.

71. Macmurdo CF, Wooderchak-Donahue W, Bayrak-Toydemir P, Le J, Wallenstein MB, Milla C, et al. RASA1 somatic mutation and variable expressivity in capillary malformation/arteriovenous malformation (CM/AVM) syndrome. Am J Med Genet Part A. 2016;170:1450-4. https://doi.org/10. 1002/ajmg.a.37613.

72. Miyatake S, Okamoto N, Stark Z, Nabetani M, Tsurusaki Y, Nakashima $M$, et al. ANKRD1 1 variants cause variable clinical features associated with KBG syndrome and Coffin-Siris-like syndrome. J Hum Genet. 2017;62:741-6. https://doi.org/10.1038/jhg.2017.24.

73. Krejci P. The paradox of FGFR3 signaling in skeletal dysplasia: Why chondrocytes growth arrest while other cells over proliferate. Mutat Res Rev Mutat Res. 2014;749:40-8.

74. Ornitz DM, Legeai-Mallet L. Achondroplasia: development, pathogenesis, and therapy. Dev Dyn. 2017;246:291-309.

75. Hafner C, Groesser L. Mosaic RASopathies. Cell Cycle. 2013;12:43-50.

76. Ilari R, Agosta G, Bacino C. 5q14.3 deletion neurocutaneous syndrome: contiguous gene syndrome caused by simultaneous deletion of RASA1 and MEF2C: a progressive disease. Am J Med Genet Part A. 2016;170:688-93. https://doi.org/10.1002/ajmg.a.37472.

77. Bienvenu T, Diebold B, Chelly J, Isidor B. Refining the phenotype associated with MEF2C point mutations. Neurogenetics. 2013;14:71-5.

78. Savarese E, Di FB, Miconi F, Cabiati G, Celi F, Crescenzi F, et al. An association of PTPN1 1 and SHOXMutations in a male presenting with syndromic growth failure. Front Endocrinol (Lausanne). 2018;9:1-4.

79. Jee YH, Baron J, Nilsson O. New developments in the genetic diagnosis of short stature. Curr Opin Pediatr. 2018;30:541-7.

80. Cizmarova M, Kostalova L, Pribilincova Z, Lasabova Z, Hlavata A, Kovacs L, et al. Rasopathies_-dysmorphic syndromes with short stature and risk of malignancy. Endocr Regul. 2013;47:217-22.

81. Finken MJJ, Van Der Steen M, Smeets CCJ, Walenkamp MJE, De Bruin C, Hokken-Koelega ACS, et al. Children born small for gestational age: differential diagnosis, molecular genetic evaluation, and implications. Endocr Rev. 2018;39:851-94

82. Hood RL, Lines MA, Nikkel SM, Schwartzentruber J, Beaulieu C, Nowaczyk MJM, et al. Mutations in SRCAP, encoding SNF2-related CREBBP activator protein, cause Floating-Harbor syndrome. Am J Hum Genet. 2012;90:308-13.

83. Gruber W, Scheidt T, Aberger F, Huber CG. Understanding cell signaling in cancer stem cells for targeted therapy — can phosphoproteomics help to reveal the secrets? Cell Commun Signal. 2017. https://doi.org/ 10.1186/s12964-017-0166-1.

84. Doll S, Gnad F, Mann M. The case for proteomics and phosphoproteomics in personalized cancer medicine. Proteomics Clin Appl. 2019;13:1800113

85. Hirayama M, Kobayashi D, Mizuguchi S, Morikawa T, Nagayama M, Midorikawa $U$, et al. Integrated proteomics identified novel activation of dynein IC2-GR-COX-1 signaling in neurofibromatosis type I (NF1) disease model cells. Mol Cell Proteomics. 2013;12:1377-94.

86. Kobayashi T, Aoki Y, Niihori T, Cavé H, Verloes A, Okamoto N, et al. Molecular and clinical analysis of RAF1 in Noonan syndrome and related disorders: dephosphorylation of serine 259 as the essential mechanism for mutant activation. Hum Mutat. 2010;31:284-94. https:// doi.org/10.1002/humu.21187.

87. Eminaga S, Bennett AM. Noonan syndrome-associated SHP-2/Ptpn11 mutants enhance SIRPa and PZR tyrosyl phosphorylation and promote adhesion-mediated ERK activation. J Biol Chem. 2008;283:15328-38.

88. Arrington JV, Hsu CC, Elder SG, Andy TW. Recent advances in phosphoproteomics and application to neurological diseases. Analyst. 2017; 142:4373-87.

89. Brossier NM, Prechtl AM, Longo JF, Barnes S, Wilson LS, Byer SJ, et al. Classic Ras proteins promote proliferation and survival via distinct phosphoproteome alterations in neurofibromin-null malignant peripheral nerve sheath tumor cells. J Neuropathol Exp Neurol. 2015;74:568-86. 
90. Paardekooper Overman J, Yi J-S, Bonetti M, Soulsby M, Preisinger C, Stokes MP, et al. PZR coordinates Shp2 Noonan and LEOPARD syndrome signaling in zebrafish and mice. Mol Cell Biol. 2014;34:2874-89.

91. Overman JP, Preisinger C, Prummel K, Bonetti M, Giansanti P, Heck A, et al. Phosphoproteomics-mediated identification of Fer kinase as a target of mutant Shp2 in Noonan and LEOPARD syndrome. PLoS ONE. 2014;9:e0106682

92. Corallino S, Iwai LK, Payne LS, Huang PH, Sacco F, Cesareni G, et al. Alterations in the phosphoproteomic profile of cells expressing a non-functional form of the SHP2 phosphatase. New Biotechnol. 2016:33:524-36. https://doi.org/10.1016/j.nbt.2015.08.002.

93. Patrakitkomjorn S, Kobayashi D, Morikawa T, Wilson MM, Tsubota N, Irie A, et al. Neurofibromatosis type 1 (NF1) tumor suppressor, neurofibromin, regulates the neuronal differentiation of PC12 cells via its associating protein, CRMP-2. J Biol Chem. 2008;283:9399-413.

94. Eisenhardt AE, Sprenger A, Röring M, Herr R, Weinberg F, Köhler M, et al. Phospho-proteomic analyses of B-Raf protein complexes reveal new regulatory principles. Oncotarget. 2016;7:26628-52

95. Whitehouse CM, Dreyer RN, Yamashita M, Fenn JB. Electrospray interface for liquid chromatographs and mass spectrometers. Anal Chem. 1985;57:675-9. https://doi.org/10.1021/ac00280a023.

96. Barnes H, Larsen B, Tyers M, van der Geer P. Tyrosine-phosphorylated Low Density Lipoprotein Receptor-related Protein 1 (LRP1) Associates with the Adaptor Protein SHC in SRC-transformed Cells. J Biol Chem. 2001;276:19119-25.

97. Jebar AH, Hurst CD, Tomlinson DC, Johnston C, Taylor CF, Knowles MA FGFR3 and Ras gene mutations are mutually exclusive genetic events in urothelial cell carcinoma. Oncogene. 2005;24:5218-25.

98. Masih-Khan E, Trudel S, Heise C, Li Z, Paterson J, Nadeem V, et al. MIP-1a (CCL3) is a downstream target of FGFR3 and RAS-MAPK signaling in multiple myeloma. Blood. 2006;108:3465-71.

99. Kang S, Dong S, Gu TL, Guo A, Cohen MS, Lonial S, et al. FGFR3 activates RSK2 to mediate hematopoietic transformation through tyrosine phosphorylation of RSK2 and activation of the MEK/ERK pathway. Cancer Cell. 2007;12:201-14.

100. Juanpere N, Agell L, Lorenzo M, De Muga S, López-Vilaró L, Murillo R, et al. Mutations in FGFR3 and PIK3CA, singly or combined with RAS and AKT1, are associated with AKT but not with MAPK pathway activation in urothelial bladder cancer. Hum Pathol. 2012;43:1573-82. https://doi. org/10.1016/j.humpath.2011.10.026

101. Yadav V, Zhang X, Liu J, Estrem S, Li S, Gong XQ, et al. Reactivation of Mitogen-activated Protein Kinase (MAPK) pathway by FGF Receptor 3 (FGFR3)/Ras mediates resistance to vemurafenib in human B-RAF V600E mutant melanoma. J Biol Chem. 2012;287:28087-98. https://doi.org/10. 1074/jbc.M112.377218.

102. Hart KC, Robertson SC, Donoghue DJ. Identification of tyrosine residues in constitutively activated fibroblast growth factor receptor 3 involved in mitogenesis, stat activation, and phosphatidylinositol 3-kinase activation. Guidotti G, editor. Mol Biol Cell. 2001;12:931-42. https://doi.org/10. 1091/mbc.12.4.931.

103. Theodorescu D, Cornil I, Fernandez BJ, Kerbel RS. Overexpression of normal and mutated forms of HRAS induces orthotopic bladder invasion in a human transitional cell carcinoma. Proc Natl Acad Sci. 1990;87:904751. https://doi.org/10.1073/pnas.87.22.9047.

104. van Rhijn BW, Lurkin I, Radvanyi F, Kirkels WJ, van der Kwast TH, Zwarthoff EC. The fibroblast growth factor receptor 3 (FGFR3) mutation is a strong indicator of superficial bladder cancer with low recurrence rate. Cancer Res. 2001;61:1265-8.

105. Agazie YM, Movilla N, Ischenko I, Hayman MJ. The phosphotyrosine phosphatase SHP2 is a critical mediator of transformation induced by the oncogenic fibroblast growth factor receptor 3. Oncogene. 2003:22:6909-18.

106. Zhu L, Lv L, Wu D, Shao J. KAT6B genetic variant identified in a short stature chinese infant: a report of physical growth in clinical spectrum of KAT6B-related disorders. Front Pediatr. 2020;8:6-11.

107. Gannon T, Perveen R, Schlecht H, Ramsden S, Anderson B, Kerr B, et al. Further delineation of the KAT6B molecular and phenotypic spectrum. Eur J Hum Genet. 2015;23:1165-70.

108. Rönnstrand L. Signal transduction via the stem cell factor receptor/cKit. Cell Mol Life Sci. 2004;61:2535-48.
109. Hers I, Vincent EE, Tavaré JM. Akt signalling in health and disease. Cell Signal. 2011;23:1515-27.

110. Nicholson KM, Anderson NG. The protein kinase B/Akt signalling pathway in human malignancy. Cell Signal. 2002;14:381-95.

111. Heron-Milhavet L, Khouya N, Fernandez A, Lamb NJ. Akt1 and Akt2: differentiating the aktion. Histol Histopathol. 2011;26:651-62.

112. Thauvin-Robinet C, Auclair M, Duplomb L, Caron-Debarle M, Avila M, St-Onge J, et al. PIK3R1 mutations cause syndromic insulin resistance with lipoatrophy. Am J Hum Genet. 2013;93:141-9.

113. Zhang X, Simerly C, Hartnett C, Schatten G, Smithgall TE. Src-family tyrosine kinase activities are essential for differentiation of human embryonic stem cells. Stem Cell Res. 2014;13:379-89.

114. Lowenstein EJ, Daly RJ, Batzer AG, Li W, Margolis B, Lammers R, et al. The $\mathrm{SH} 2$ and $\mathrm{SH} 3$ domain-containing protein GRB2 links receptor tyrosine kinases to ras signaling. Cell. 1992;70:431-42.

115. Feng G-S, Ouyang Y-B, Hu D-P, Shi Z-Q, Gentz R, Ni J. Grap is a novel $\mathrm{SH} 3-\mathrm{SH} 2-\mathrm{SH} 3$ adaptor protein that couples tyrosine kinases to the Ras pathway. J Biol Chem. 1996;271:12129-32. https://doi.org/10.1074/jbc. 271.21.12129.

116. Egorov MV, Polishchuk RS. Emerging role of Cdc42-specific guanine nucleotide exchange factors as regulators of membrane trafficking in health and disease. Tissue Cell. 2017;49:157-62.

117. Martinelli S, De Luca A, Stellacci E, Rossi C, Checquolo S, Lepri F, et al. Heterozygous germline mutations in the CBL tumor-suppressor gene cause a noonan syndrome-like phenotype. Am J Hum Genet. 2010;87:250-7. https://doi.org/10.1016/j.ajhg.2010.06.015.

118. Rossatti P, Ziegler L, Schregle R, Betzler VM, Ecker M, Rossy J. Cdc42 couples $T$ cell receptor endocytosis to GRAF1-mediated tubular invaginations of the plasma membrane. Cells. 2019:8:1388.

119. Yi JS, Perla S, Enyenihi L, Bennett AM. Tyrosyl phosphorylation of PZR promotes hypertrophic cardiomyopathy in PTPN11-associated Noonan syndrome with multiple lentigines. JCI Insight. 2020;5: 137753. https:// doi.org/10.1172/jci.insight.137753.

120. Araki T, Mohi MG, Ismat FA, Bronson RT, Williams IR, Kutok JL, et al. Mouse model of Noonan syndrome reveals cell type- and gene dosage-dependent effects of Ptpn11 mutation. Nat Med. 2004;10:849-57.

121. Carvajal-Vergara X, Sevilla A, Dsouza SL, Ang YS, Schaniel C, Lee DF, et al. Patient-specific induced pluripotent stem-cell-derived models of LEOPARD syndrome. Nature. 2010;465:808-12.

122. Cui Y, Costa RM, Murphy GG, Elgersma Y, Zhu Y, Gutmann DH, et al. Neurofibromin regulation of ERK signaling modulates GABA release and learning. Cell. 2008;135:549-60.

123. Denayer E, Ahmed T, Brems H, Van Woerden G, Borgesius NZ, CallaertsVegh Z, et al. Spred 1 is required for synaptic plasticity and hippocampus-dependent learning. J Neurosci. 2008;28:14443-9.

124. Edouard T, Combier J, Nédélec A, Bel-Vialar S, Métrich M, Conte-Auriol F, et al. Functional effects of PTPN11 (SHP2) mutations causing LEOPARD syndrome on epidermal growth factor-induced phosphoinositide 3-kinase/AKT/glycogen synthase kinase $3 \beta$ signaling. Mol Cell Biol. 2010;30:2498-507.

125. Guo W, Liu W, Chen Z, Gu Y, Peng S, Shen L, et al. Tyrosine phosphatase SHP2 negatively regulates NLRP3 inflammasome activation via ANT1dependent mitochondrial homeostasis. Nat Commun. 2017. https:// doi.org/10.1038/s41467-017-02351-0.

126. Hernández-Porras I, Fabbiano S, Schuhmacher AJ, Aicher A, Cañamero M, Cámara JA, et al. K-RasV14I recapitulates noonan syndrome in mice. Proc Natl Acad Sci USA. 2014;111:16395-400.

127. Lee Y-S, Ehninger D, Zhou M, Oh J-Y, Kang M, Kwak C, et al. Mechanism and treatment for learning and memory deficits in mouse models of Noonan syndrome. Nat Neurosci. 2014;17:1736-43.

128. Levy AD, Xiao X, Shaw JE, Sudarsana Devi SP, Katrancha SM, Bennett AM, et al. Noonan syndrome-associated SHP2 dephosphorylates GluN2B to regulate NMDA receptor function. Cell Rep. 2018;24:1523-35. https:// doi.org/10.1016/j.celrep.2018.07.006.

129. Marin TM, Keith K, Davies B, Conner DA, Guha P, Kalaitzidis D, et al. Rapamycin reverses hypertrophic cardiomyopathy in a mouse model of LEOPARD syndrome-associated PTPN11 mutation. J Clin Investig. 2011;121:1026-43.

130. Motta M, Pannone L, Pantaleoni F, Bocchinfuso G, Radio FC, Cecchetti $S$, et al. Enhanced MAPK1 function causes a neurodevelopmental 
disorder within the RASopathy clinical spectrum. Am J Hum Genet. 2020;107:499-513.

131. Mulero-Navarro S, Sevilla A, Roman AC, Lee DF, D'Souza SL, Pardo S, et al. Myeloid dysregulation in a human induced pluripotent stem cell model of PTPN11-associated juvenile myelomonocytic leukemia. Cell Rep. 2015;13:504-15.

132. Niihori T, Aoki Y, Okamoto N, Kurosawa K, Ohashi H, Mizuno S, et al. HRAS mutants identified in Costello syndrome patients can induce cellular senescence: possible implications for the pathogenesis of Costello syndrome. J Hum Genet. 2011;56:707-15.

133. Rodriguez-Viciana P, Tetsu O, Tidyman WE, Estep AL, Conger BA, Cruz $M S$, et al. Germline mutations in genes within the MAPK pathway cause cardio-facio-cutaneous syndrome. Science (80-). 2006;311:1287-90.

134. Schreiber J, Grimbergen L, Overwater I, Van Der VT. Mechanisms underlying cognitive deficits in a mouse model for Costello Syndrome are distinct from other RASopathy mouse models. Sci Rep. 2017. https:// doi.org/10.1038/s41598-017-01218-0.

135. Sewduth RN, Pandolfi S, Steklov M, Sheryazdanova A, Zhao P, Criem N et al. The Noonan syndrome gene Lztr1 controls cardiovascular function by regulating vesicular trafficking. Circ Res. 2020:126:1379-93.

136. Takahara S, Inoue S, Miyagawa-Tomita S, Matsuura K, Nakashima Y, Niihori T, et al. New Noonan syndrome model mice with RIT1 mutation exhibit cardiac hypertrophy and susceptibility to $\beta$-adrenergic stimulation-induced cardiac fibrosis. EBioMedicine. 2019;42:43-53. https://doi.org/10.1016/.ebiom.2019.03.014.

137. Wakioka T, Sasaki A, Kato R, Shouda T, Matsumoto A, Miyoshi K, et al. Spred is a sprouty-related suppressor of Ras signalling. Nature. 2001;412:647-51.
138. Yeh E Dao DQ Wu ZY Kandalam SM Camacho FM Tom C et al. Patient-derived iPSCs show premature neural differentiation and neuron type-specific phenotypes relevant to neurodevelopment. Mol Psychiatry. 2018;23:1687-98

139. UniProt Consortium T. UniProt: the universal protein knowledgebase. Nucleic Acids Res. 2018;46:2699-2699. https://doi.org/10.1093/nar/ gkw1099.

140. Ruzicka L, Howe DG, Ramachandran S, Toro S, Van Slyke CE, Bradford YM, et al. The Zebrafish Information Network: new support for noncoding genes, richer Gene Ontology annotations and the Alliance of Genome Resources. Nucleic Acids Res. 2019;47:D867-73.

141. Hornbeck PV, Zhang B, Murray B, Kornhauser JM, Latham V, Skrzypek E. PhosphoSitePlus, 2014: mutations, PTMs and recalibrations. Nucleic Acids Res. 2015:43:D512-20.

142. R Core Team. R: A language and environment for statistical computing. Vienna: R Foundation for Statistical Computing; 2020

143. RStudio Team. RStudio: Integrated Development for R. Boston: RStudio, Inc.; 2020

144. Kolde R. Pheatmap: pretty heatmaps. R package version 1.0.12.

\section{Publisher's Note}

Springer Nature remains neutral with regard to jurisdictional claims in published maps and institutional affiliations.
Ready to submit your research? Choose BMC and benefit from:

- fast, convenient online submission

- thorough peer review by experienced researchers in your field

- rapid publication on acceptance

- support for research data, including large and complex data types

- gold Open Access which fosters wider collaboration and increased citations

- maximum visibility for your research: over $100 \mathrm{M}$ website views per year

At $\mathrm{BMC}$, research is always in progress.

Learn more biomedcentral.com/submissions 